\title{
Cell Transplantation and "Stem Cell Therapy" in the Treatment of Myopathies: Many Promises in Mice, Few Realities in Humans
}

\author{
Daniel Skuk ${ }^{1,2}$ \\ ${ }^{1}$ Neurosciences Division-Human Genetics, CHUQ Research Center-CHUL, Quebec, QC, Canada \\ ${ }^{2}$ Unité de Recherche en Génétique Humaine, Centre Hospitalier de l'Université Laval, 2705 boulevard Laurier, Québec,
} QC, Canada G1V 4G2

Correspondence should be addressed to Daniel Skuk; daniel.skuk@fmed.ulaval.ca

Received 14 July 2013; Accepted 21 August 2013

Academic Editors: S. V. Brodsky, W. Lim, and C. Marchese

Copyright (C) 2013 Daniel Skuk. This is an open access article distributed under the Creative Commons Attribution License, which permits unrestricted use, distribution, and reproduction in any medium, provided the original work is properly cited.

\begin{abstract}
Myopathies produce deficits in skeletal muscle function and, in some cases, progressive and irreversible loss of skeletal muscles. The transplantation of myogenic cells, that is, cells able to differentiate into myofibers, is an experimental strategy for the potential treatment of some of these diseases. The objectives pursued by the transplantation of these cells are essentially three: (a) the fusion with the patient's myofibers to obtain the expression of therapeutic proteins into them, (b) the neoformation of new functional myofibers in skeletal muscles that were too degenerated by the progressive degeneration, and (c) the formation of a new pool of healthy donor-derived satellite cells. Although the repertoire of myogenic cells appears to have expanded in recent years, myoblasts are the only cells that have been demonstrated to engraft in humans. The present work aims to make a comprehensive review of the subject, from its beginnings to recent advances, including the preclinical experience in different animal models and recent clinical findings.
\end{abstract}

\section{Introduction}

Myopathies are characterized by different degrees of localized or generalized muscle weakness from muscular etiology. This is the common symptom in a clinical picture that varies from an entity to another. Myopathies are divided into acquired and inherited; the second group is divided into main groups such as muscular dystrophies, metabolic myopathies, mitochondrial myopathies, and congenital structural myopathies. Among this group of diseases, Duchenne muscular dystrophy (DMD) probably concentrates most of the efforts for developing new therapeutic strategies. For this reason, this entity will be the focus of this review. Many considerations, however, would apply to other myopathies.

The motives by which DMD draws a lot of attention are the relative frequency of the illness for a rare disease (50 cases per million is the prevalence for the male population) and its ominous prognosis: progressive skeletal muscle degeneration in the limbs and trunk, evolving during infancy and puberty, leading to almost a complete loss of skeletal muscles in those regions, restrictive respiratory insufficiency, and ultimately death by respiratory or cardiac complications. In the natural evolution of the disease, most patients die before the age of 20. Progress in supportive care, essentially noninvasive mechanical ventilation, assisted coughing, and cardioprotective medication, have made half of these patients now reach 40 years of life in advanced countries [1]. Contrasting with the improvement in prolonging patient's survival, muscle degeneration cannot be stopped by any treatment. This ends in a severe and irreversible motor loss which, from the point of view of the function of voluntary muscles, is equivalent to quadriplegia.

To conceive a treatment, it is essential to understand the etiology and pathogenesis of the disease. The molecular defect in the origin of DMD is a severe deficiency of dystrophin, a subsarcolemmal protein that seems necessary for the stability of the sarcolemma during the cycles of myofiber contraction and relaxation [2]. In the most accepted pathogenesis of DMD, dystrophin deficiency causes frequent myofiber necrosis due to sarcolemmal breaks during these contraction and relaxation cycles [2]. Myofiber necrosis is followed by myofiber regeneration in repetitive cycles until the regenerative capacity is exhausted. At this point, myofiber 
regeneration becomes less and less effective, and the amount and size of myofibers progressively decrease. During this process, fibrosis and fat infiltration develop into the muscles and eventually replace their functional structure. What once was muscle becomes a disorganized structure of connective and adipose tissues with few remaining atrophic myofibers. In many cases, it is not possible to identify myofibers in biopsies, beyond the presence of surviving muscle spindles [3].

Understanding this etiology and pathogenesis involves that treatments for DMD may have different objectives at different stages of the disease. In early stages, we need to restore dystrophin expression in the myofibers to stop or to slow down the progression of the disease. At later stages, we need to generate new muscle. The first objective (dystrophin restoration) is shared by two main approaches, sometimes interconnected: gene therapy and cell transplantation (throughout the paper, I will make reference to "cell transplantation" and not to "cell therapy." On one hand, so far there is no therapy based on cells for this disease. On the other hand, I think the expression "cell therapy" is vague. If we refer to organs instead of cells, we can easily understand that the accuracy of the terminology "liver transplantation" cannot be replaced by "liver therapy." The first definition makes it clear what kind of treatment is-transplantation-while the second do not). The second objective (regenerating the skeletal muscle) is beyond the pure domain of gene therapy and would only be affordable by strategies of regenerative medicine, essentially cell transplantation and tissue engineering. Cell transplantation in skeletal muscles is thus one of the main potential future treatments for myopathies such as DMD.

Cell transplantation implies that the implantation into the body is of either differentiated cells that constitute the parenchyma and eventually the stroma of tissues and organs, or precursor cells with the capacity to differentiate into the formers. The skeletal muscle is a highly specialized tissue with specific characteristics that on the one hand may make difficult cell transplantation strategies and on the other provides clues for these strategies. What hinders cell transplantation is the crucial organization of the muscle, which depends on the precise three-dimensional arrangement of myofibers, the long multinucleated syncytial elements that can reach several centimeters in length. It seems impossible to use the differentiated cells of the skeletal muscle (myofibers) for transplantation. What gives certain clues for cell transplantation strategies is the fact that myofibers have an efficient regeneration mechanism, based on the presence of specific mononuclear progenitor cells that under certain conditions have the capacity to be activated, proliferate, and fuse among them to reconstitute a myofiber. Cell transplantation in myology uses the second possibility: the transplantation of precursor cells.

\section{What Properties a Mononuclear Cell Needs to Be Transplantable in Skeletal Muscles?}

To be useful in the treatment of skeletal muscle diseases, a mononuclear cell must have at least one of three specific properties (Figure 1).
(1) The capacity to incorporate their nuclei into the myofibers of the receiver.

(2) The capacity to form new functional myofibers by the fusion of the grafted cells between them.

(3) The capacity to originate a pool of mononuclear muscle-precursor cells in the skeletal muscles.

To have all three properties is ideal for a myogenic cell that is proposed for transplantation as a treatment of myopathies. However, any of these properties could be useful in one way or another, though their importance is variable. The incorporation into preexisting myofibers is evidently crucial for the molecular correction in recessive hereditary myopathies, but the formation of new myofibers becomes more important when the disease have caused significant loss of myofibers.

2.1. Incorporation of Grafted Nuclei into Preexisting Myofibers (Figure 1(e)). Lipton and Schultz reported for the first time in 1979 that myoblasts grafted intramuscularly fused with the myofibers of the recipient in rats and quails and that, in a minor amount, they fused among themselves to form new small myofibers [4]. Fusion of the transplanted cells with the recipient's myofibers gives rise to a phenomenon that was called gene complementation. Gene complementation means that the myofiber's syncytia express proteins coded both by the endogenous and exogenous genoma [5] (Figure 1(e)). These myofibers expressing exogenous and endogenous proteins in the same syncytium are called hybrid [6]. Exogenous nuclei can then express therapeutic genes in myofibers that previously suffered from a genetic deficiency. The first report of gene complementation restoring a genetically missing protein in a myopathic animal was of Partridge et al. in 1989 [7]. They transplanted normal mouse myoblasts in skeletal muscles of $m d x$ mice, a mouse strain that develops a myopathy caused by the lack of dystrophin as DMD in humans. They detected dystrophin in several myofibers after followups of at least 3 weeks. Similar results were reported thereafter by other researchers $[8,9]$, and this has become a routine in the research of myogenic-cell transplantation. Gene complementation in myofibers of humans was unequivocally confirmed in at least 3 clinical trials of myoblast transplantation [10-13] (Figure 2).

A key factor that makes myogenic-cell implantation difficult is the fact that intracellular proteins in myofibers remain near the nucleus of origin, in a region named the nuclear domain [14]. This is determined both because the mRNA diffuses only $100 \mu \mathrm{m}$ from the nucleus [15] and because the proteins have also a limited spreading [16]. Consequently, proteins from donor origin remain in the myofiber regions in which the transplanted cells fused (Figure 1(e)). The nuclear domain's length varies for each protein, depending on factors such as if they remain soluble or anchored to stationary cellular components [16]. This factor conditions the analysis of transplantation results, and a striking example was the comparison between green fluorescent protein and dystrophin. Following transplantation of cells expressing dystrophin and green fluorescent protein in $m d x$ mice, 


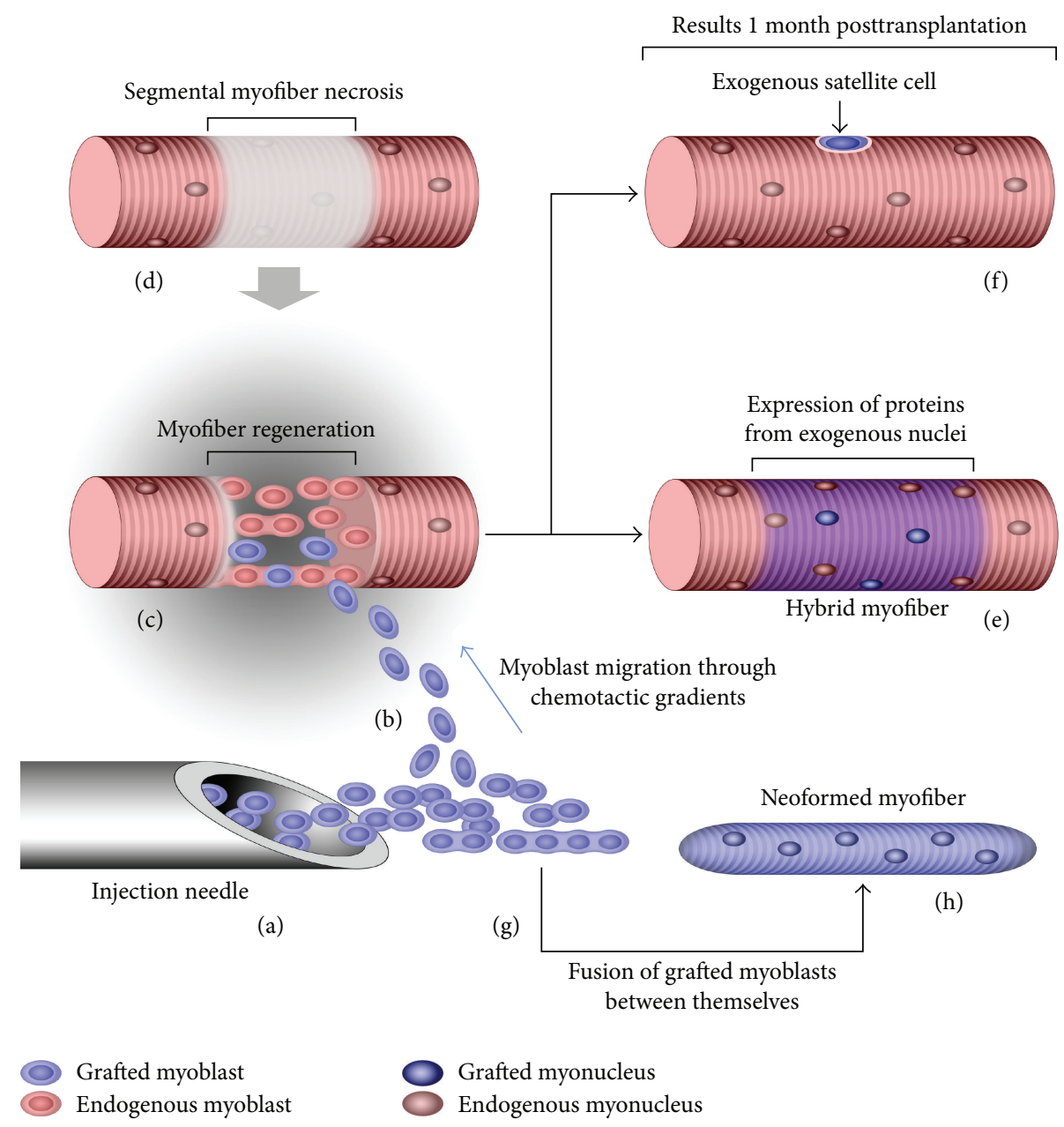

FIGURE 1: Properties required in mononuclear precursor cells to be useful for cell transplantation in myology. The figure makes reference to myoblasts because they are the only cells in which the three properties have been demonstrated convincingly by different independent groups and are the only ones that showed at least some of them in clinical conditions. The endogenous elements are depicted in red, and the exogenous grafted elements are in blue. After intramuscular injection (a), the grafted myoblasts are collected essentially in perimysial spaces, as observed in nonhuman primates. From there, at least some of them migrate guided by chemotactic gradients ((b), the gradient is represented in gray) towards myofibers in regeneration (c). Myofiber regeneration (c) is the consequence of myofiber necrosis, which can be complete or (more frequently in myopathies and intramuscular cell transplantation) segmental (d). These migrating myoblasts are recruited in the process of myofiber regeneration, and they fuse with the endogenous myoblasts (c). Once regeneration is completed, the incorporation of the grafted myoblasts in the process of regeneration gives rise to hybrid myofibers (e). In addition to the proteins synthesized by endogenous nuclei, hybrid myofibers produce exogenous proteins around the exogenous myonuclei (e). So far, myoblasts are the only mononuclear precursor cells that were demonstrated to posses this property in clinical conditions. Some of the grafted cells, in addition, can give raise to new satellite cells (f). Finally, the grated cells can fuse between themselves (g) to give rise to neoformed myofibers (h). Our clinical observations strongly suggest that transplanted myoblasts can form small new myofibers in humans, a property that must be improved to meet a clinical role.

dystrophin was detected through about $116 \mu \mathrm{m}$ in myofibers, while green fluorescent protein diffused up to $1500 \mu \mathrm{m}$ [17]. It is particularly important to consider this factor when the results of a transgenic label in transplantation experiments are extrapolated to a therapeutic protein, such as dystrophin in DMD.

This territorial restriction of proteins in myofibers was remarked in some clinical trials of normal myoblast transplantation in DMD patients. Although without confirming whether this was specifically donor-derived dystrophin,
Gussoni et al. [18] reported dystrophin expression ranging from $300 \mu \mathrm{m}$ to more than $450 \mu \mathrm{m}$ (the longest wide of their analysis) in the myofibers of DMD patients that were transplanted with normal myoblasts. We performed a quantitative analysis in a DMD patient in which we could detect specifically the donor-derived dystrophin, and we confirmed the territorial expression of this dystrophin in myofiber regions from at least $700 \mu \mathrm{m}$ to more than $2 \mathrm{~mm}$ [12]. In these cases, the length of dystrophin expression depends not only on the nuclear domain, but also on the 


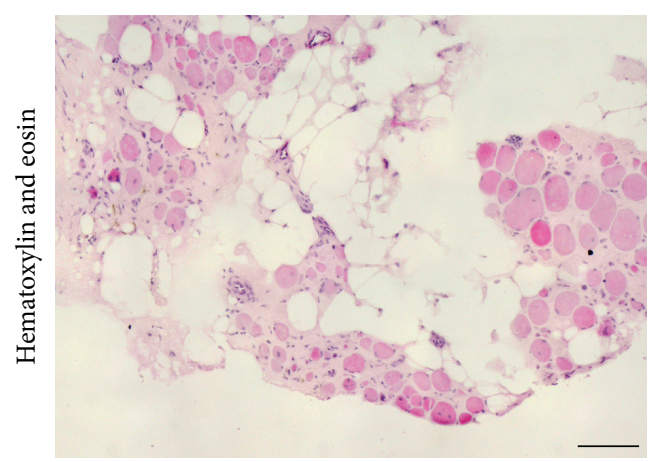

(a)

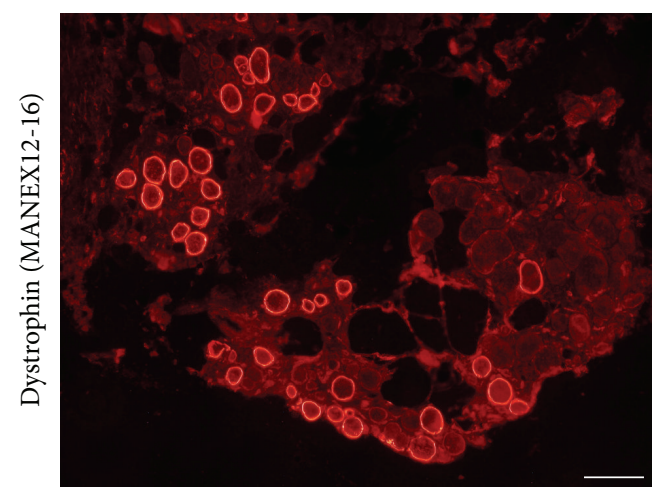

(b)

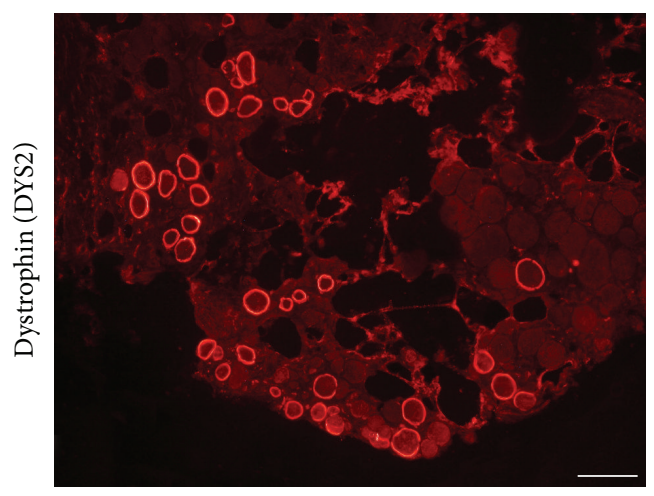

(c)

FIGURE 2: Gene complementation after myoblast transplantation restored the expression of dystrophin in the myofibers of a DMD patient. The figure shows serial cross-sections of a muscle biopsy done in the gastrocnemius of a 26-year-old DMD patient, corresponding to a site that was transplanted 1 month before with myoblasts proliferated in culture from a muscle biopsy performed in the deltoid of his father. Sections were stained with hematoxylin and eosin, and for the fluorescent immunodetection of dystrophin they were with MANEX12-16 (an antibody that detects an epitope coded by the exons 12 to 16 of the dystrophin gene) and DYS2 (an antibody that detects an epitope coded by the exons 77 to 79 of the dystrophin gene). The section stained with hematoxylin and eosin shows a skeletal muscle with an intense substitution by adipose tissue, isolated groups of small-sized myofibers, and some fibrosis. The fluorescent immunodetection of dystrophin in the serial sections shows that an important proportion of these myofibers exhibited subsarcolemmal staining, both with an antibody that recognizes epitopes deleted in the patient (MANEX12-16, deletion was from exons 1 to 44 ) and with an antibody that recognizes the carboxyterminal portion of the protein (DYS2). Both immunodetections were negative in the contralateral gastrocnemius injected with saline instead of normal myoblasts. Scale bars $=100 \mu \mathrm{m}$.

length of myofiber regeneration in which grafted cells were integrated.

2.2. Neoformation of Myofibers. In a degenerative myopathy as DMD, muscle weakness worsens as a consequence of the progressive reduction of myofiber size and number. In other myopathies, such as some forms of congenital muscular dystrophy, a severe loss of myofibers can be present at birth. The optimal treatment for the advanced phases of these diseases must involve not only molecular correction but also neoformation of functional myofibers.

As said above, Lipton and Schultz were the first to report that transplanted myoblasts can fuse among themselves to form new although small myofibers [4] (Figures 1(g) and 1(h)). So far, this property was unequivocally confirmed only in transplantation of myoblasts. Myoblast transplantation was the only type of myogenic cell transplantation in mice that was able to completely or almost completely regenerate muscles destroyed by different acute treatments, recovering muscle mass and strength [19-22]. Nevertheless, these acute experimental conditions are different from a chronic degenerative myopathy. In these mouse experiments, the damage was massive and acute, preserving the endomysial scaffold, in which the basal lamina seems important for an orderly muscle regeneration as observed in rats and rabbits [23]. On the contrary, myofiber necrosis is insidious in chronic degenerative myopathies, and the muscle is progressively replaced by adipose and/or fibrous tissue, losing the endomysial support.

In some mouse experiments, myoblast transplantation was able to form new myofibers in the absence of a previous endomysial scaffold. The most clear example was the capacity of myoblasts implanted subcutaneously to neoform ectopic muscles [24]. Another example was the demonstration that intramuscularly implanted myoblasts fused among themselves to form new myofibers in $m d x$ mice in which muscle irradiation was done previous to transplantation [25]. 


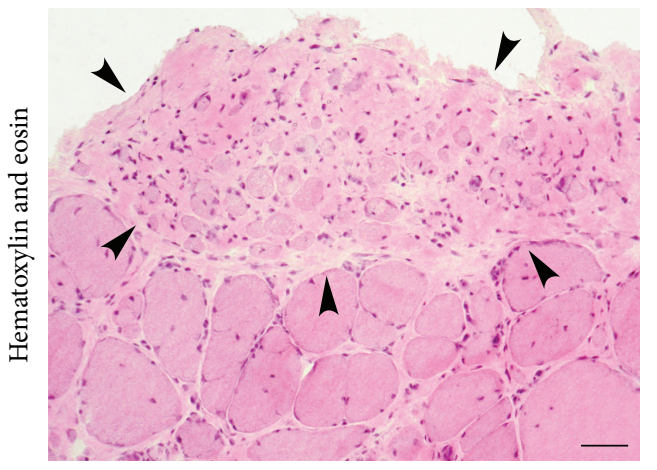

(a)

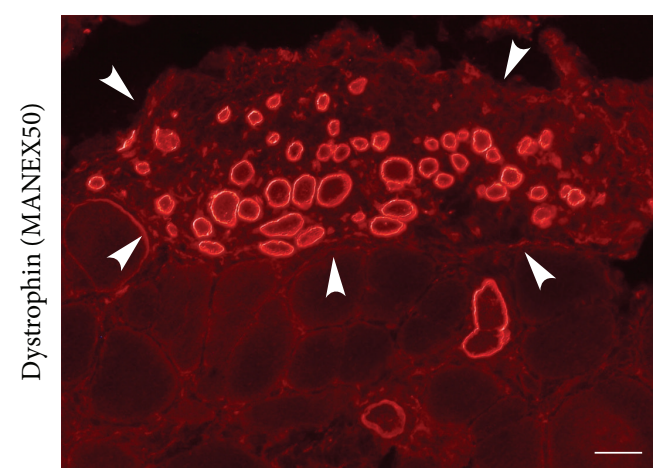

(b)

FIGURE 3: Potential neoformation of small myofibers after myoblast transplantation in a DMD patient. The figure shows serial cross-sections of a muscle biopsy done in the tibialis anterior of a 16-year-old DMD patient, corresponding to a site that was transplanted 1 month before with myoblasts proliferated in culture from a muscle biopsy performed in the deltoid of his father. The sections were stained with hematoxylin and eosin (a) and for the fluorescent immunodetection of dystrophin with MANEX50 (b). This antibody detects an epitope coded by the exon 50 of the dystrophin gene, which was the exon deleted in the patient, confirming that the dystrophin is from donor origin. There is an accumulation of small myofibers dispersed into an extrafascicular accumulation of the connective tissue ((a), between arrowheads). All of these small myofibers are donor-derived dystrophin+. We interpreted that this corresponds to myofiber neoformation due to the fusion of the implanted myoblasts among them. This was based on the fact that these focal accumulations of connective tissue with small myofibers were observed only in the cell-grafted sites, and that these small myofibers were small and entirely donor-derived dystrophin+. Some observations in nonhuman primates support this hypothesis. Scale bars $=50 \mu \mathrm{m}$.

However, the most important issue remains insufficiently studied, that is, whether myogenic cell transplantation could form functional myofibers in skeletal muscles that degenerated to fibrosis and/or fat substitution. There is a study showing that myotubes and regenerating myofibers developed across implants of adipose tissue inserted in regenerating skeletal muscles in mice, suggesting that perhaps adipose tissue in dystrophic muscle would not be an impediment for the neoformation of myofibers [26]. Some studies suggested that certain factors should be taken into account in this context. It was reported that the presence of fat in the muscles of mice could induce the transdifferentiation of some human muscle precursor cells into adipocytes, specifically those expressing CD34 [27]. If confirmed in further studies, this could mean that cell sorting could be useful to separate CD34-negative cells for transplantation, since they did not transdifferentiate into fat cells [27].

Our clinical observations suggest that a similar potential to neoform myofibers exists after myoblast transplantation in humans [11]. In some DMD patients allotransplanted with normal myoblasts, we observed clusters of short and small-sized myofibers, all of which expressed donor-derived dystrophin, dispersed throughout focal accumulations of connective tissue located in the perimysium (Figure 3). These focal accumulations of small myofibers were observed only in the cell-grafted sites and were in agreement with the fact that the intramuscularly injected myoblasts form accumulations in the perimysium. An important question was whether such neoformation should be functionally relevant. To be functional, myofibers must be innervated and must be longer and larger than those observed. However, it is encouraging that most of them were parallel to the recipients' myofibers (Figure 3). This was maybe because fusion took place in a tissue submitted to continuous stretching, which helps forming myotubes and myofibers aligned in the lines of force according to the direction of stretching $[28,29]$. This observation may stimulate further research to improve the capacity of myoblast transplantation to form new myofibers in skeletal muscles of DMD patients.

2.3. Generation of Donor-Derived Satellite Cells. If some transplanted cells can remain as mononuclear muscleprecursor cells in the muscle, and specifically as satellite cells (Figure 1(f)), this would imply that the effect of transplantation may not be limited to the early fusion of the grafted cells. These graft-derived satellite cells would be able to participate later in muscle hypertrophy and regeneration. Perhaps the amount of myofibers expressing dystrophin in DMD patients transplanted with normal myoblasts may increase over time, provided that there is a phenomenon similar to that reported in $m d x$ mice, that is, the expansion of clusters of myofibers expressing revertant dystrophin [30].

This property was widely reported transplanting mouse and human myoblasts in mice. In a seminal study, Yao and Kurachi grafted mouse myoblasts into mouse muscles, sampling the grafted muscle up to 5 months later [31]. They found that up to $2 \%$ of the myoblast colonies that they obtained in vitro from these muscles derived from the graft, proving that some myoblasts remained as mononuclear precursor cells in the host muscles [31]. Moreover, these myoblasts were able to fuse with myofibers after a new transplantation, and some of them remained again as mononuclear cell precursors in the recipient muscles [31]. Thereafter, Gross and Morgan grafted mouse myoblasts into irradiated muscles and produced myofiber necrosis 4 times at 3-week intervals using notexin, a specific myofiber toxin that preserves mononuclear cells [32]. Since there were regenerating donorderived myofibers after each notexin injection, this was 


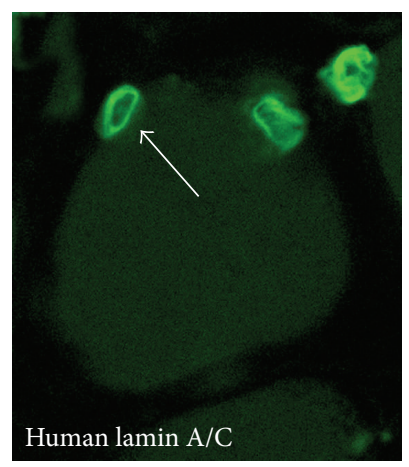

(a)

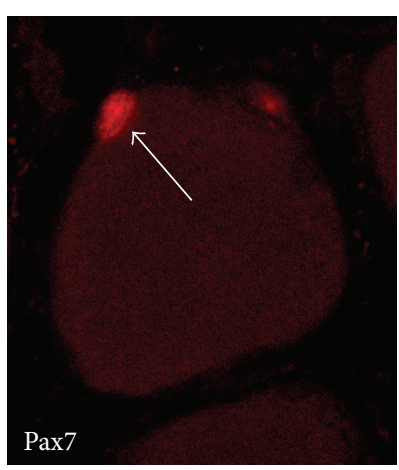

(b)

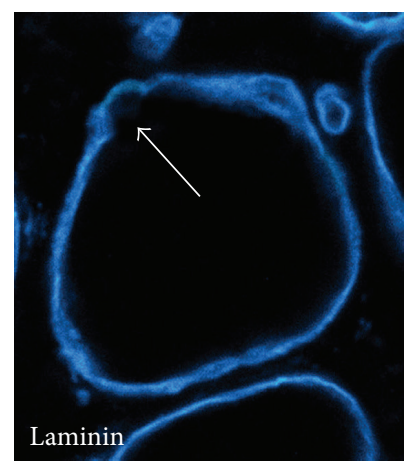

(c)

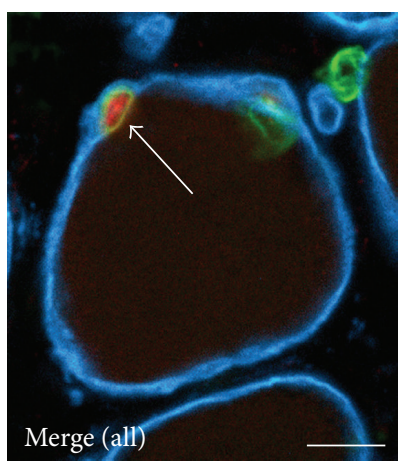

(d)

FIGURE 4: Exogenous satellite cells are formed by the transplantation of human myoblasts in immunodeficient mice. The figure shows a single myofiber in a cross-section of a skeletal muscle of an immunodeficient mouse transplanted with myoblasts from an adult human donor 4 weeks before. Different elements are evidenced by fluorescent immunodetection in confocal microscopy. The peripheral nuclear labeling of human lamin A/C (green fluorescence) evidenced human nuclei in the periphery of the myofiber (visible by contrast enhancement). One of them (arrows) shows a typical intranuclear staining of Pax7, a marker of satellite cells (red fluorescence). Immunodetection of laminin (blue fluorescence) evidenced that this nucleus is in addition in the periphery of the myofiber and inside the basal lamina, that is, in the anatomical position of satellite cells (see Figure 5). Scale bar $=10 \mu \mathrm{m}$.

another evidence that some grafted myoblasts remained in the host muscle as mononuclear precursor cells competent to contribute to myofiber regeneration even after repeated muscle injuries. Similar results were obtained by monitoring in vivo fluorescence imaging the fate of fluorescent-labeled mouse myoblasts [33].

Irintchev et al. were the first to provide evidence that some transplanted myoblasts became satellite cells in mice $[22,24]$. After reconstituting destroyed muscles by myoblast transplantation, they identified donor-derived mononuclear cells that were adjacent to myofibers and were M-cadherin+, a characteristic of satellite cells [22]. In another study, they created ectopic muscles by subcutaneous transplantation of myoblasts [24]. These neoformed muscles also had mononuclear cells expressing M-cadherin in a typical satellite-cell position [24]. Other research teams further identified donorderived satellite cells in muscles transplanted with mouse myoblasts, by immunodetection of CD34 and Pax7 [33, 34].

Transplantation of human myoblasts in immunodeficient mice reproduced the previous results obtained with mouse myoblasts. We observed abundant human-derived satellite cells in mouse muscles one month after the transplantation of myoblasts cultured from adult humans [35] (Figure 4). These human-derived satellite cells explain the presence of donorderived muscle-precursor cells evidenced in experiments of culture and retransplantation in immunodeficient mice [35] and confirm preliminary observations suggesting that some human nuclei in isolated human/mouse hybrid myofibers were satellite cells [36]. Human fetal myoblasts also produced mononucleated muscle-precursor cells following transplantation in immunodeficient mice [37].

Other human-derived cells that were reported to form donor-derived satellite cells following transplantation in immunodeficient mice, with different efficiency, were muscle-derived CD133+ cells [38], muscle-derived aldehydedehydrogenase+ cells [39], and intra-arterially delivered pericytes [40].
Our last clinical trial of cell transplantation in DMD patients suggests that formation of donor-derived satellite cells could also occur following myoblast transplantation in humans. In some of the DMD patients that received myoblast allotransplantations, we detected donor-derived nuclei in an anatomical position susceptible to correspond to satellite cells $[11,35]$.

\section{Myogenic Cells}

Several cells were reported as myogenic in experiments of transplantation and were proposed as potentially transplantable in clinical myology. First of all, there are the cells that are the mainstay of myofiber regeneration, that is, satellite cells [41] and their progeny, myoblasts [42]. Until a few years, muscle regeneration seemed well defined in terms of cell types that take the myogenic pathway, summarized in the following sequence of differentiation: satellite cell $\rightarrow$ myoblast $\rightarrow$ myotube $\rightarrow$ myofiber. However, different myogenic cells outside of this "axis" have been reported recently in cell transplantation experiments performed primarily in mice. It remains to determine to what extent these other myogenic cells play a physiological role in myofiber regeneration, and if so, how they play this role. The most consistent evidence at present indicates that the main role in myofiber regeneration is played by satellite cells and myoblasts [43-46]. The question that is still pending is to what extent the role of satellite cells in myofiber regeneration is the principal over other accessory regeneration pathways, or whether this role is the only one.

3.1. Satellite Cells and Myoblasts: the Mainstay of Myofiber Regeneration. The earliest references of myoblasts were dated at least from 1915, when these cells were observed for the first time in vitro [47]. The term myoblasts defines the proliferating mononuclear myogenic cells that fuse among them to form 
myotubes, elongated and narrow syncytia that under appropriate conditions mature to form myofibers, the contractile multinucleated cells of the skeletal muscle parenchyma. This term applies to every instance in which this phenomenon takes place, that is, during histogenesis in utero, in postnatal myofiber regeneration, and in vitro culture of muscle cells. It could be convenient to use the adjective "adult" for the myoblasts that are responsible for myofiber regeneration in postnatal life [48]. This would establish a difference with embryonic and fetal myoblasts that form skeletal muscles during histogenesis. This distinction is important because adult cells do not necessarily display the same molecular expression profiles than embryonic or fetal counterparts [49]. One example of the different molecular dependence of myoblasts in the embryonic, fetal, neonatal, and adult ages are the different relevance of myogenic determinants such as Pax3 and Pax7 [50]. Noteworthy, adult myoblasts have different behavior and morphology than embryonic and fetal myoblasts in cell culture [51].

Satellite cells (Figure 5) were discovered by Mauro in 1961 during ultrastructural studies of skeletal muscles in frogs [52]. Following a series of morphological studies on muscle regeneration by histology and electron microscopy [53], it was accepted that the regeneration of damaged myofibers takes place in a stereotyped way after the activation of satellite cells, their conversion into proliferating myoblasts, the fusion of myoblasts among each other to form myotubes, and the differentiation of myotubes into myofibers [53]. This process allows to regenerate an entire myofiber or to fill the gap in a myofiber that underwent segmental necrosis. This sequence of myogenic differentiation begins to be well defined from the molecular point of view. A family of transcription factors controlling this process were identified in recent years, for example, Myf5, MyoD, MRF4, and myogenin [54]. As an example, proliferating myoblasts express Myf5 and MyoD, [55] while myogenin is associated with fusion and terminal differentiation [56].

The niche of satellite cells is between the sarcolemma and the myofiber's basal lamina (Figure 5). They remain latent in their niche until an event such as segmental or total necrosis of a nearby myofiber is produced. At least some of them meet the characteristics of stem cells; that is, they are capable of asymmetrical division, giving rise on one side to myoblasts that will participate in myofiber regeneration and on the other side to satellite cells that will reconstitute the pool of these cells $[57,58]$. Satellite cells can be released from skeletal muscle fragments using standard enzymatic procedures of cell culture and can easily be subcultured as myoblasts, which have the ability to fuse together to form myotubes that eventually differentiate into myofibers [59]. This simplicity to be obtained and expanded in vitro, facilitated the use of myoblasts for cell transplantation approaches not only in myology but also, later, in cell-based therapies for heart pathologies [60]. Partridge, Grounds, and Sloper set the starting point of myoblast transplantation in 1978, when they suggested that "in subjects suffering from inherited recessive myopathies, muscle function might be restored if normal myoblasts could be made to fuse with defective muscle fibers" [42]. So far, myoblasts were the only myogenic cells

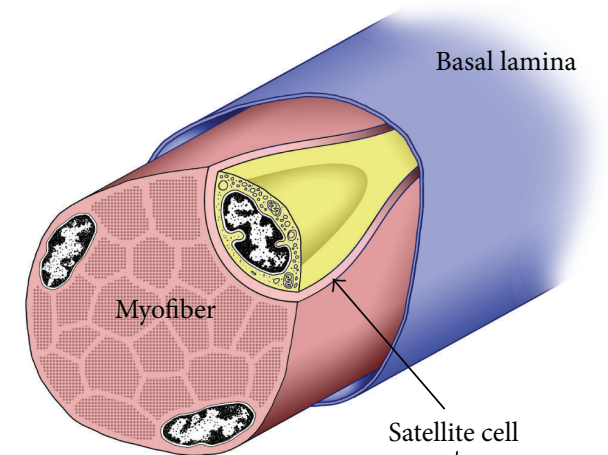

(a)

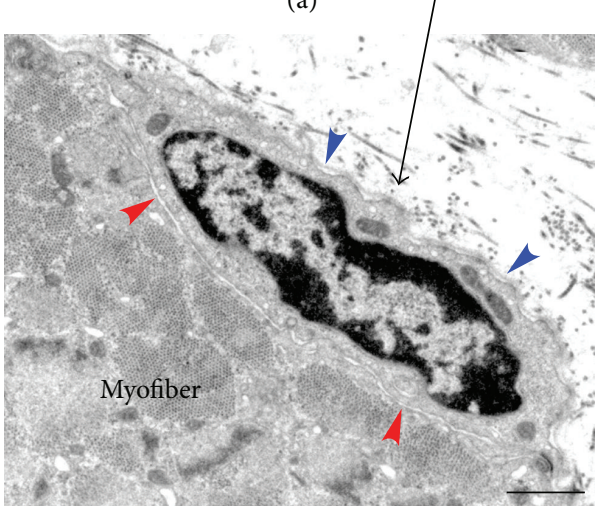

(b)

FIGURE 5: Schematic representation of the location of the satellite cell (yellow) in its niche between the sarcolemma and the basal lamina (a). (b) shows a satellite cell (between arrowheads) of a nonhuman primate observed by electron microscopy. Blue arrowheads indicate the basal lamina, and red arrowheads indicate the thin space between the sarcolemma and the satellite cell. The dense nucleus with clumped chromatin and the little undifferentiated cytoplasm are typical of satellite cells. Scale bar $=1 \mu \mathrm{m}$.

that were proved unequivocally to engraft in humans and produce myofibers expressing donor-derived dystrophin in DMD patients [10-13] (Figures 2 and 3). Unlike the other cells that will be described below, myoblasts have been studied by several different teams in a wide range of animal models such as mice [61], rats [62, 63], dogs [64, 65], monkeys [66], rabbits $[67,68]$, and pigs [69].

3.2. Heterodox Myogenic Cells. Satellite cells can completely regenerate myofibers without needing other sources of myogenic cells [43]. Moreover, recent murine models, in which satellite cells can be conditionally depleted, demonstrated that ablation of satellite cells prevents myofiber regeneration [44-46]. This shows that the participation of other cells in myofiber regeneration, if exists, is irrelevant from a physiological point of view.

In spite of that, other cells with the capacity to participate in myofiber regeneration were reported under specific experimental conditions. These cells with myogenic potential can be divided in two groups: cells resident in the muscle and circulating cells. Heterodox myogenic cells that were 
reported as resident in the skeletal muscle are musclederived stem cells [70], mesoangioblasts [71, 72], pericytes [73], myoendothelial cells [74], CD133+ cells [75], cells with aldehyde dehydrogenase (ALDH) activity [39], PW1+/Pax7interstitial cells [76], and $\beta$-4-integrin+ cells [77]. Some of these myogenic cells were reported to be associated with the vasculature, for example, mesoangioblasts/pericytes and $\beta$-4-integrin + cells. Others were reported to be in the interstitium between myofibers, for example, ALDH+ cells and PW1+/Pax7- cells. In some cases, it remains the doubt of whether some of these apparently different cells could be the same [78].

Most of these cells were reported in mice and in some cases in humans. Their capacity to be myogenic in vivo, however, was observed generally only in experimental conditions of transplantation in mice. Other animal species were used only in specific cases; for example, mesoangioblasts were obtained from dogs and allotransplanted in dogs [72]. What is specially intriguing is that some of these heterodoxal myogenic cells were reported to be more efficient than myoblasts to participate in myofiber regeneration following transplantation in mice. However, when they are in situ and non transplanted, none of these heterodoxal myogenic cells can regenerate myofibers by themselves in mice $[44,45]$.

It is thus pertinent to remark that the results obtained with some of these cells are generally restricted to the work of one laboratory and have not been reproduced by other research teams. Readers are reminded of this deficit in the current literature and are encouraged to use their own judgment to assess the following data.

Circulating Cells from the Bone Marrow. In the 80s, there was some interest in studying whether circulating cells from the bone marrow could participate in muscle regeneration. In a seminal study, Grounds reconstituted the bone marrow of irradiated mice with hematopoietic cells from a second strain of mice, the two strains being homozygous for one of the two different isoenzyme forms of the enzyme glucose-6phosphate isomerase [79]. Analyzing the isoenzyme patterns of regenerated and host muscle, she found no evidence that bone marrow precursor cells contributed to myofiber regeneration. Moreover, no circulating myogenic cells were observed infiltrating mouse muscles whose cellular constituents were completely killed by repeated freezing [80]. Several independent groups reported that inhibiting the capacity of proliferation of muscle resident cells by high doses of ionizing radiation causes muscle atrophy that is not prevented by circulating cells [81-84]. The conclusion at that time was that there was no substantial involvement of the bone marrow in muscle regeneration.

These findings seemed to be contradicted by two later studies. In one of them, the reconstitution of the hematopoietic compartment by bone marrow transplantation after whole body irradiation of normal mice was followed by the capacity of the donor cells to participate partially in muscle regeneration [85]. In the other one, the intravenous administration of normal hematopoietic stem cells in $m d x$ mice was followed by dystrophin expression in some myofibers
[86]. For some researchers, this suggested that muscular dystrophies such as DMD could be treated by hematopoietic cell transplantation. Nevertheless, it was confirmed later that the efficacy of normal bone marrow transplantation to induce the expression of donor-dystrophin in a transgenic dystrophin-deficient mouse (a model with almost complete absence of revertant myofibers) was irrelevant, as few as $0.25 \%$ of dystrophin + myofibers during the mouse lifespan [87]. Even if it was reported in mice that some bone marrow cells express proteins of the muscle, the transplantation of a fraction enriched 10 -fold in these cells did not increase the percentage of dystrophin+ myofibers [88].

The inefficiency of hematopoietic cell transplantation to participate in myofiber regeneration and to induce donorderived dystrophin expression was confirmed in dogs [89]. In observation periods ranging from 28 to 417 days after transplantation of normal hematopoietic cells in 7 dogs with dystrophin-deficient muscular dystrophy, there was no evidence nor for participation in myofiber regeneration neither for formation of myogenic mononuclear cells [89]. There were also two clinical cases in which the reconstitution of the hematopoietic compartment with cells of a normal donor confirmed the inefficiency of this approach. One of them was a DMD patient that received bone marrow transplantation at the age of 1 year to treat an X-linked severe combined immunodeficiency; 13 years after that treatment, donor nuclei were detected by fluorescent in situ hybridization in only $0.5-$ $0.9 \%$ of the myofibers [90]. The other case was a boy in which chronic granulomatous disease was treated at 16 months of age with transplantation of umbilical cord-derived stem cells to reconstitute the hematopoietic compartment and was diagnosed later with DMD [91]. Several studies demonstrated that the presence of donor-derived hematopoietic cells was unable to correct the genetic defect in the skeletal muscles [91].

An interesting hypothesis to explain the rare participation of some bone marrow derived cells in myofiber regeneration was that this phenomenon would be caused by the occasional "trapping" of a macrophage in the fusogenic process of muscle regeneration [92]. Indeed, macrophages have the possibilities to fuse among them, and they infiltrate in large numbers the damaged myofibers. It was also shown that the vast majority of the rare myonuclei derived from circulating bone marrow cells in mice remains silent [93].

Mesoangioblasts. Mesoangioblasts constitute a cell type discovered in the aorta of mouse embryos [94] and described later in vessels of postnatal mice [95]. The irruption of these cells in the field of cell transplantation in myology was impressive, once a paper published in 2003 reported that the intra-arterial delivery of normal mesoangioblasts produced extensive molecular correction and functional improvements in mice with muscular dystrophy due to a deficiency of alpha-sarcoglycan [71]. In dogs with muscular dystrophy due to a deficiency of dystrophin, the intra-arterial delivery of normal canine mesoangioblasts produced extensive recovery of dystrophin expression, improving muscle structure and eventually muscle function [72]. While the validity of the 
results in term of improvement of muscle function were a subject of controversy [96-98], these cells are those that have been reported to produce the most spectacular results in a model other than mice. Results in dogs are especially important, because the myogenicity of most of the other cells (with the exception of myoblasts) was observed only following transplantation in mouse. For this reason, the results of an ongoing clinical trial of transplantation of mesoangioblasts derived from normal donors into DMD patients are being awaited with great expectancy [99].

Pericytes. This chapter overlaps to some extent with the previous. Since mesoangioblasts express pericyte markers [40], the group that discovered these cells suggested that, when obtained from adult humans, they must be called "pericyte-derived cells" [95]. These cells generated abundant human dystrophin+ myofibers when implanted into immunodeficient $m d x$ mice [40]. This attracted the attention of researchers towards pericytes. Pericytes are contractile cells that envelop the endothelial cells of capillaries and postcapillary venules [100]. Besides the function specifically linked to the vasculature, it was reported that they have oligopotential capacity, being able to differentiate into osteocytes, chondrocytes, and adipocytes [101, 102]. Results on the myogenicity of pericytes are not homogeneous, varying from one laboratory to another. One group reported that humanderived pericytes formed human myofibers after implantation in immunodeficient mouse muscles, independently of their tissue of origin [73]. However, although retinal pericytes seemed to be myogenic under certain conditions in vitro [103], our experience grafting retinal pericytes from monkeys in immunodeficient mice was negative (unpublished results). Indeed, the research team that discovered mesoangioblasts reported myogenicity only in pericytes derived form skeletal muscles [40]. The comparison of pericytes and myoblasts following intramuscular transplantation in mice has been contradictory: one study reported that pericytes were more efficient than myoblasts [73], while another demonstrated the opposite [40]. It was reported in mice that intra-arterially delivered pericytes may reconstitute, to a limited extent, the satellite cell pool [40]. However, there is no still evidence of whether they can give rise to new pericytes in vivo, with myogenic potential.

It has been suggested that pericytes might have some physiological involvement in myofiber regeneration in young mice, although this participation would depend on the activity of satellite cells and disappear in adult mice [104]. Given also that the regenerative capacity of mice is different from that of humans [105], it would be appropriate to explore this phenomenon also in animal models more similar to humans.

Myoendothelial Cells. The results reported with mesoangioblasts aroused the interest in the potential discovery of other myogenic cells related to the blood vessels. A subset of satellite cells coexpressing endothelial antigens was reported by histology in humans [74]. Similar cells were revealed by flow cytometry (CD56+/CD34+/CD144+/CD45-) and were called for this reason "myoendothelial" [74]. This adjective have been already used in the 60 s to refer to endothelial cells containing filaments resembling microfibrils in electron microscopy studies [106]. In one experiment, myoendothelial cells transplanted into muscles of immunodeficient mice produced donor-derived myofibers [74].

CD133+ Cells. CD133, first identified as a surface marker for some circulating human hematopoietic and endothelial progenitors, was then detected in stem and progenitor cells from various tissues [107]. CD133+ cells were obtained from blood fused with myofibers when delivered intra-arterial in immunodeficient $m d x$ mice [108]. The intramuscular and intra-arterial delivery of genetically corrected CD133+ cells isolated from blood and muscles of DMD patients produced dystrophin expression in immunodeficient $m d x$ mice, improving the muscle structure and function [75]. A clinical trial was conducted in which muscle-derived CD133+ cells were injected in a small muscle region in DMD patients [109]. The results of this trial cannot be considered as particularly relevant, since it was an autologous graft, and a very small number of cells were injected only with 3 shots in a small muscle region.

Muscle-Derived Stem Cells (MDSC). This term is now somewhat ambiguous, as several authors have referred to it for the cells that were obtained from the skeletal muscle by different means but showed some properties of stem cells, such as pluripotency. The most frequent use is for mouse cells that were fortuitously obtained in culture as a consequence of using a specific sequence of preplating [110]. It was observed that the earlier attaching cells were committed myogenic progenitors (myoblasts), whereas the late attaching fraction was a population of multipotent stem cells that were thus called MDSC [70]. These cells isolated by preplating were reported to produce 10 -fold more hybrid myofibers than myoblasts following intramuscular injection in mice [70]. However, other independent groups did not observe differences between the transplantation of myoblasts and MDSC in mouse [111]. Other researchers called MDSC the side population cells isolated from skeletal muscle [112]. Others, a subpopulation of slow adherent cells derived from mouse skeletal muscle that can proliferate for months as myospheres [113].

ALDH + Cells. ALDH activity is a hallmark of primitive progenitor cells present in human bone marrow, umbilical cord blood, and peripheral blood, which have high reconstitution capacities in vivo [39]. Cells with ALDH activity were recently described in the endomysium of human skeletal muscles, although in low frequency [39]. There were two subpopulations of ALDH+ cells according with CD34 expression, and the CD34-negative fraction showed to be myogenic following intramuscular transplantation in immunodeficient mice.

PW1+/Pax7-Interstitial Cells and $\beta$-4-Integrin+ Cells. These cells recently identified in the endomysium of mice were showed to be myogenic $[76,77]$. They were not reported in human skeletal muscle. 


\section{Delivery of Myogenic Cells to Skeletal Muscles}

The protocol to deliver myogenic cells to the skeletal muscle is a crucial second stage after identifying adequate cells for transplantation. The challenge is important in generalized myopathies such as DMD given the volume of tissue to be treated: skeletal muscle contributes $40 \%$ to $50 \%$ to the body weight [114]. Although not all skeletal muscles need to be treated to achieve a benefit, the ideal is to treat as maximum as possible. Only two routes appear as available to administrate the cells: intramuscular and intravascular.

Intramuscular has been so far the most used route for cell transplantation studies in myology. Its main constraint, when applied to humans or nonhuman primates [115] is that it requires a high number of cell injections and a meticulous cell delivery in each injection. Although this technical constraint would be probably affordable, it is clear that an easier method of cell implantation, if it exists, would be preferable. In this sense, the intravascular delivery has a priori some advantages, the most obvious being that the grafted cells should be distributed even to muscles that cannot be easily targeted by intramuscular injections.

There are two possibilities of intravascular delivery: intravenous and intra-arterial. A priori, the intravenous route has the disadvantages of indiscriminately distribute the cells throughout the body and the fact that the cells will find a first barrier in the capillary network of the lungs. Conversely, intra-arterial injection can send the injected cells mainly to the required location. Both routes were tested in rodents, and the advantage of the intra-arterial route was evident. Myoblasts engrafted in damaged muscles following intraarterial delivery [116] but the intravenous delivery was unsuccessful even after extensive muscle injury [117]. Intravenous delivery of muscle side population cells in $m d x$ mice led to $<1 \%$ of hybrid myofibers against $5-8 \%$ when delivered intraarterial [118]. The intra-arterial route became the preferential route in other studies devoted to study the intravascular injection of other myogenic cells in mice [71, 119] and dogs [72]. Mesoangioblasts are the only cells in which the intra-arterial infusion was reported to be efficient in animal models of muscular dystrophies, including dogs [71, 72]. Some positive results were also reported with CD133+ cells in mice [108]. In most myogenic cells, the route that has proven to produce efficient engraftment is the intramuscular injection.

4.1. Intramuscular Injection of Myogenic Cells. The main restriction of the intramuscular implantation of myogenic cells is that, when done in a muscle in which the only disturbing factor is the transplant itself, the engraftment occurs essentially in the trajectories of the injection needle $[115,120]$. This is clearly observed in muscle transversal sections of skeletal muscles grafted with myoblasts in nonhuman primates; the engraftment takes the form of irregular "stripes" of hybrid myofibers that match with the previous cell injection trajectories [120-123] (Figure 6). This pattern was called by the author as bands of engraftment [120]. The pattern of donor-dystrophin expression in DMD patients transplanted with normal myoblasts was sometimes similar although in other cases it was less defined [11-13]. Perhaps this is because in DMD patients there is spontaneous myofiber necrosis in addition to the damage produced by the cell injection.

The pattern of bands of engraftment was attributed until recently to an inability of the grafted cells to migrate. Erroneously, this "inability to migrate" is persistently mentioned as the main factor explaining the local fusion of grafted myoblasts in skeletal muscles and serves still as an argument to justify the search of other myogenic cells that are expected to perform differently in transplantation. We also previously thought that the bands of engraftment were due to the fact that the grafted myoblasts remained stationary at the sites of injection, fusing only with myofibers in close contact with them. However, we also mentioned a second possibility, that is, that muscle regeneration is mandatory to draw the grafted cells fusing with the recipient myofibers and that, at least in a normal muscle, this occurs generally only in the regions damaged by the injections $[61,124]$. Now, we know that grafted myoblasts can migrate several millimeters in the muscle of macaques, but seemingly only to participate in myofiber regeneration $[125,126]$ (Figures 1(b) and 1(c)).

In fact, intramuscularly-injected cells are not collected in the injection trajectories [125]. Even if delivered carefully along the injection trajectories, the cell suspension is collected mostly in the perimysium [125]. There, the accumulations of grafted cells form irregular patterns oriented independently of the injection trajectories [125]. This distribution is explained by the fact that intramuscular transplantation implies the injection of a cell suspension, a liquid that needs to create a space into the host tissue to be contained therein. To do that, it must compress and eventually dissect the tissue. The injected liquid will be submitted to shear compressive stress and pushed to flow towards weak points. As we observed in monkeys, the perimysium seems to be the weaker part in the muscle structure, susceptible of being dissected in cleavage planes by the injected liquid [125]. Since the most prominent result of myoblast transplantation in monkeys is the fusion with intrafascicular myofibers in the previous injection-needle trajectories, this implies that either fusion with the myofibers is done by a few myoblasts remaining in the trajectories, not easily visible in the histological sections, and/or that grafted myoblasts migrate from the perimysial collections towards the myofibers damaged by the injection needle. The fact that myoblasts transplanted subcutaneously in monkeys can migrate into the muscle to fuse with myofibers mechanically damaged supports the second hypothesis [125].

Myoblasts move during myofiber regeneration guided by gradients of chemoattractant factors released from both the damaged myofibers and the inflammatory cells recruited by the muscle damage [127]. Injured myofibers release chemotactic factors to recruit macrophages, and, in turn, these macrophages induce strong chemoattraction on myoblasts, secreting factors such as platelet-derived growth factor, transforming growth factor-beta, basic fibroblast growth factor, and leukemia inhibitory factor [128]. Hepatocyte growth factor [129] and thymosin $\beta 4$ [130] are also released in the site 


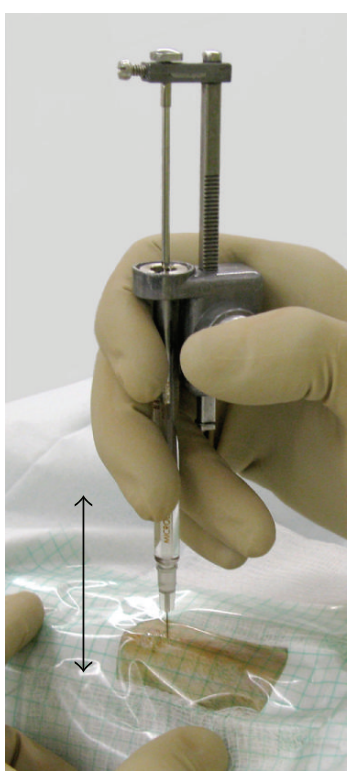

(a)

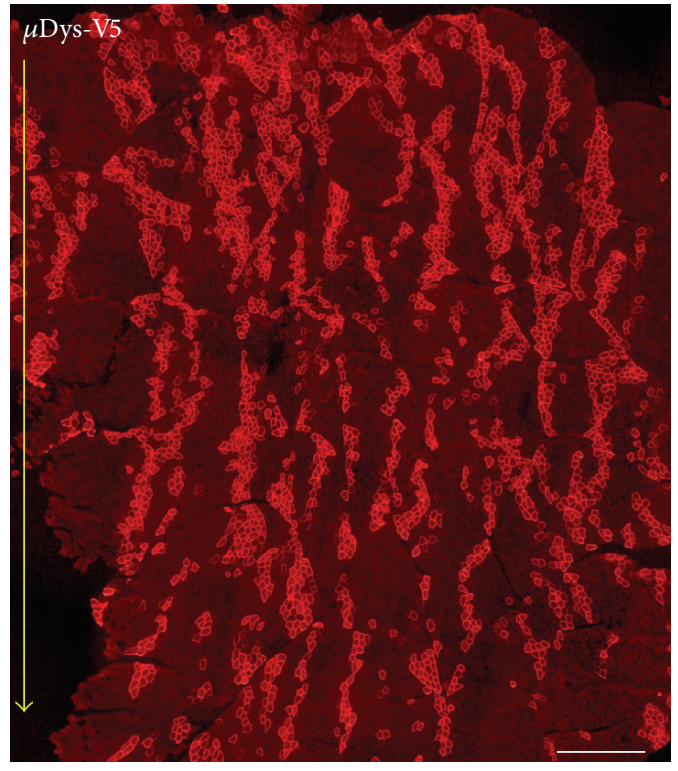

(b)

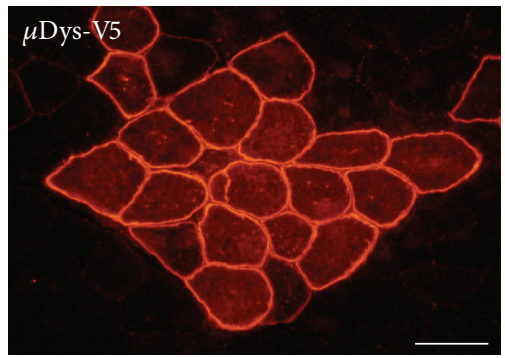

(c)

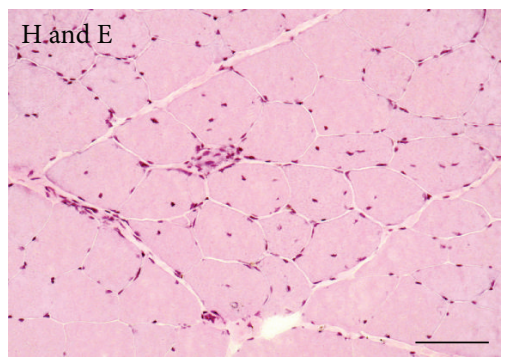

(d)

FIGURE 6: One of the techniques developed by the author for the intramuscular transplantation of myoblasts in nonhuman primates is illustrated. In this case, the protocol implies matrices of parallel close intramuscular injections, which is done to deliver myogenic cells the most homogeneously as possible throughout muscle regions that do not receive another treatment than the cell injections. For small to medium-sized regions, this is easily done with a Hamilton syringe attached to a repeating dispenser (a). The pattern of cell injections is controlled with a sterile transparent dressing with a $5 \mathrm{~mm}$ grid, adhered on the cell-grafted region (the biceps brachii of a macaque in the picture). The black arrow indicates the repetitive movements of penetration and subsequent removal of the needle, during which cells are injected by pressing the button on the device. After one month, the fusion of the grafted cells with the recipient's myofibers is analyzed in cross sections of muscle biopsies, using histological techniques to detect the transgenic proteins that labeled the grafted cells ((b) and (c)). In this case, a cross section of a monkey muscle is grafted with transgenic myoblasts labeled with a microdystrophin coupled with a V5 peptide tag ( $\mu$ Dys-V5). Hybrid myofibers expressing proteins coded by the myonuclei of the grafted cells are observed by fluorescent immunodetection of the V5 peptide tag. The distribution of the hybrid myofibers in "bands of engraftment" (b) reproduces the pattern of the original cell-injection trajectories (indicated by the yellow arrow). At a higher magnification (c), the labeling is essentially sarcoplasmic according to the normal location of dystrophin, although some intracellular staining is also observed. A serial section of (c) stained with hematoxylin and eosin is shown (d) to illustrate the structure of the muscle. Some of the V5-positive myofibers exhibit internal nuclei, indicating recent regeneration. Scale bars: $1 \mathrm{~mm}(\mathrm{~b})$ and $100 \mu \mathrm{m}((\mathrm{c})$ and $(\mathrm{d}))$.

of myofiber damage and are chemoattractant for myoblasts. Myoblast does not only need myofiber regeneration to be incorporated into the host myofibers; it was proposed that intact myofibers may have repulsive interactions for myoblasts [131], which may prevent the fusion of grafted myoblasts with intact myofibers even in the case of close contact.

The local fusion of the implanted myoblasts would not be a problem if the donor-derived proteins were capable of diffusing throughout each myofiber. However, given that proteins are restricted to nuclear domains, which are very short in the case of dystrophin, myogenic-cell transplantation must insure a diffuse fusion of the implanted myoblasts throughout the muscle. If myoblasts are injected in a saline solution and without muscle pretreatments, the only possibility to achieve a significant homogeneous expression of donorderived proteins is to perform cell injections very close to each other and through the full muscle thickness [121].

With this technique, the amount of muscle expressing a donor-derived protein depends on the number of injections per muscle volume; that is, the more injections done, the better result is achieved in terms of donor-protein expression in the muscle, such as $\beta$-galactosidase or dystrophin in monkeys [122, 132] or dystrophin in DMD patients [11-13]. Looking to make a difference with the earlier clinical trials in which myoblast transplantation was performed by few injections too far apart from each other, the author has called this strategy a high-density injections protocol [124]. In this case, "density" means the amount of injections per volume of muscle.

4.2. Increasing the Engraftment of Myogenic Cells. It is obvious that increasing the engraftment by escalating the number of cell injections is not the ideal solution (although should not be set aside if it is the only opportunity to treat a patient with muscular dystrophy). To avoid that, the amount of muscle expressing a therapeutic protein (e.g., dystrophin in DMD) after one cell injection should be increased.

The factors reducing gene complementation to the vicinity of cell injections seem to be only two: (a) the grafted cells fuse only with regenerating myofibers around the injection trajectory and (b) proteins remain in nuclear domains. 
Therefore, the possibilities to reduce the number of injections are also two: (a) to make grafted cells fuse more diffusely, and (b) to increase the nuclear domain of the therapeutic protein.

When the predominant idea in this field was that the "lack of migration ability" was the key factor to explain the local fusion of the grafted cells, several studies attempted to attack this problem by inducing in the grafted myoblasts the secretion of enzymes that are crucial for the intratissular motion of cells by degrading the extracellular matrix [133138]. Some of these studies reported an improved migration of myoblasts under particular experimental conditions in vitro and in vivo in mice. Nonetheless, tests in nonhuman primates exposing myoblasts to motogenic factors (basic fibroblast growth factor and insulin-like growth factor 1) enhanced their migration in vitro and in some in vivo conditions in immunodeficient mice, but myoblasts fused always in the trajectory of cell injections following intramuscular allotransplantation in macaques [137]. For the rest, this underlines that cell behaviors obtained in vitro or in special in vivo experimental conditions in mice are not necessarily representative of the problem in clinical conditions.

Indeed, the problem is not that myoblasts do not migrate, but that they do not migrate as we would like them to. Myoblasts (and probably other myogenic cells) are not supposed to have the physiological function of migrating to fuse indiscriminately with nondamaged myofibers but rather to regenerate myofibers that are totally or partially necrosed. Thus, it is pertinent to consider whether this property can be achieved in myogenic cell transplantation. We should accept for the moment that we have no choice than trying to use these physiological properties to develop transplantation strategies accordingly. Otherwise, to obtain an "intelligent migration," we should be able to create a complex transplantation context that may include the appropriate chemoattractant gradients to make myogenic cells spread throughout the muscle, the induction in these cells of the ability to penetrate the basal lamina without the help of inflammatory cells, the inhibition of potential repulsive factors in intact myofibers, and the induction in quiescent myofibers of the molecular signals required for cell fusion interactions.

Since myofiber regeneration is required to attract the grafted cells to fuse with the myofibers, many experiments increased the engraftment simply by increasing the number of regenerating myofibers at the time of transplantation. This simple strategy was far more successful than the studies that tried just to enhance the intrinsic capacity of myoblasts to migrate. One of the most typical approaches to achieve that is the intramuscular injection of myotoxins. Among these myotoxins there are the phospholipases derived from snake venoms, like notexin and cardiotoxin, which are regularly used in mice $[9,139]$ and were tested in rabbits [140] and the local anesthetic bupivacaine, used in rats $[62,63]$. Looking for a method more potentially applicable in humans, a study in mice increased myofiber regeneration in $m d x$ mice by intense muscular exercise, almost doubling the success of myoblast transplantation [141].

One common strategy to further enhance the engraftment of the transplanted myogenic cells in mice is to inhibit the proliferation of satellite cells in the muscle that receives the graft. In the absence of intrinsic competitors for myofiber regeneration, the participation of grafted cells seems to be favored. The most frequent experimental method to inhibit the proliferation of the satellite cells is to submit the skeletal muscles to high doses of ionizing radiation before transplantation $[9,19,20,139,142]$. Another possibility (more accessible to laboratories that do not have access to irradiation equipment) is cryodamage. In this case, freezing the recipient muscles combines myofiber necrosis with killing the recipient's satellite cells, and it was used in mice as a pretreatment to increase the engraftment of the implanted myogenic cells [21, 22, 36, 38].

It is experimentally easy to destroy the tiny muscle of a small rodent to obtain a good engraftment of myogenic cells. However, reproducing the same in the large muscles of large mammals is far more problematic. We tested the coinjection of myoblasts with notexin in nonhuman primates $[121,143]$. This clearly expanded the engraftment when the injections were very concentrated in a small volume of muscle [121, 143], but it was not so in the case of parallel injections separated by $5 \mathrm{~mm}$ [121]. Conversely, we failed to consistently expand the engraftment using bupivacaine, which was useful in rats $[62,63]$. This may be due to the fact that this local anesthetic is less so myotoxic in primates than in rats [144]. In the best of the cases, it is clear that large amounts of myotoxin should be injected intramuscularly to treat whole muscles. The problem is that intramuscularly injected substances are rapidly absorbed leading to the risks of a systemic effect of toxins. Regarding cryodamage, which kills all the cells of the tissue, only the tiny muscles of small mammals with good regenerative capacity can regenerate well after that treatment, but this treatment would cause irreparable destruction in muscles of large mammals. The author recently tested the use of intramuscular electroporation as a method to produce specific myofiber damage and massive myofiber regeneration in skeletal muscles of primates [126]. This method consistently increased the engraftment of transplanted myoblasts [126] (Figure 7).

The possibility of increasing the nuclear domain of donorderived proteins did not deserve much attention. There is only one study in $m d x$ mice that reported that this was possible, in this case by transplanting transgenic myoblasts overexpressing dystrophin [145]. In this experiment, there was a threefold expansion of dystrophin's nuclear domain [145].

4.3. Tools for Intramuscular Cell Transplantation. In clinical conditions, a protocol of myogenic cell transplantation by "high density of injections" makes the manual use of single precision syringes adequate only for small volumes of muscles $[11,13]$. Performed in this manner, the procedure is extremely slow and demanding in terms of permanently reaching the cell delivery in the right depth.

In a first approach to improve the technique, we have tested some dispensers used for repetitive delivery of small volumes of liquid in serological analysis [123]. The author found the monosyringe dispenser PB600-1 from Hamilton 
Control

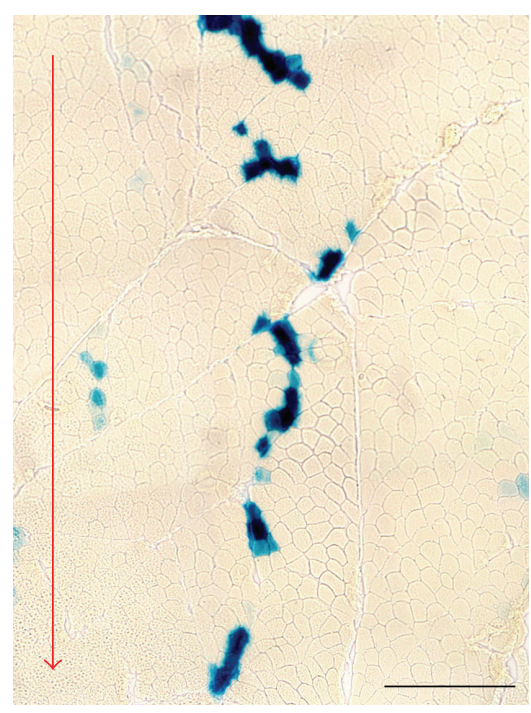

(a)

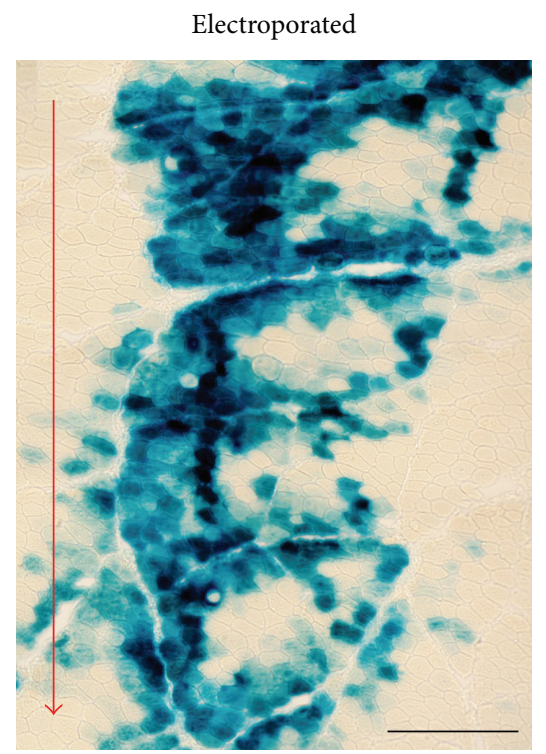

(b)

FIGURE 7: Expansion of the myoblast engraftment in nonhuman primates after skeletal muscle electroporation. The figure shows transversal sections of muscle biopsies taken 1 month after intramuscular transplantation of $\beta$-galactosidase-labeled myoblasts in skeletal muscles of macaques. The sections correspond to sites in which isolated injections of myoblasts were done, perpendicular to the myofibers and delivering $25 \mu \mathrm{l}$ of cell suspension during the needle withdrawal. They are stained for $\beta$-galactosidase detection (greenish-blue precipitate). The red arrows indicate the direction of the original needle penetration during transplantation. In one case, the injection was done in a skeletal muscle that was not pretreated (control), and in the other, the cell injection was done in a site submitted to electroporation ( 3 pulses of $400 \mathrm{~V} / \mathrm{cm}$, duration of $5 \mathrm{~ms}$ and delay of $200 \mathrm{~ms}$ ). $\beta$-galactosidase+ myofibers are disposed as a thin and discontinuous band corresponding to the injection trajectory in the control site, while the engraftment is quite large in the electroporated site, showing that the grafted myoblasts have fused abundantly with myofibers out of the injection trajectories. Scale bars $=0.5 \mathrm{~mm}$.

specially useful, which becomes his standard instrument for intramuscular cell transplantations in nonhuman primates $[123,132]$ (Figure 6). The same device was used by the author for myoblast transplantation in several muscles of an adult DMD patient [12], and another research group had tested it for myoblast transplantation in rabbits [68]. Nevertheless, the clinical use of these devices is limited to small muscles or muscle regions and, yet again, the accuracy required to deliver cells specifically in the muscle through a thick skin is a challenge.

For that reason, the author believed that it is important to develop specific instruments addressed to the percutaneous intratissular injection of cells in clinical conditions. In collaboration with robotic engineers, we developed the first prototype of a semimanual device that can deliver very small volumes of cell suspension homogeneously through the intramuscular trajectory of several needles at the same time [146] (Figure 8). This prototype was designed also to avoid as much as possible delivering cells in the skin and hypodermis [146]. The prototype accomplished a satisfactory task during myoblast transplantation sessions in whole muscles of macaques and showed that to create such tools it was technically possible. Indeed, an optimal semi-manual cellinjector should benefit of further improvements for human use.

\section{The Survival of the Myogenic Cell Graft}

5.1. The Early Survival of the Myogenic Cells. A commonplace in transplantation of myogenic cells is to affirm that myoblast transplantation is limited by the early death of the majority of the transplanted cells. This is not exact because this early death does not preclude achieving optimum transplantation results. In myoblast transplantation in macaques (the experimental animal model more similar to human), it is possible to increase the engraftment by increasing the number of transplanted cells to achieve an optimal graft [120]. That means that, ultimately, if there is a loss of myoblasts early after transplantation, this loss can be compensated by transplanting more cells. Finding a method to reduce the early death, in this case, would have the hypothetical advantage of allowing grafting smaller amounts of cells to obtain optimum results. Otherwise, the level of cell engraftment is notably dependent on the parameters used for cell implantation, such as the density of injections [122] and the amount of cells delivered per injection trajectory [120].

Indeed, myoblasts have a bad reputation in this issue merely because the problem was extensively studied in them, using several methods to analyze the cell death and survival, postulating different hypothesis to explain this phenomenon and testing several strategies to improve their survival. For other myogenic cells, either the problem was never studied 


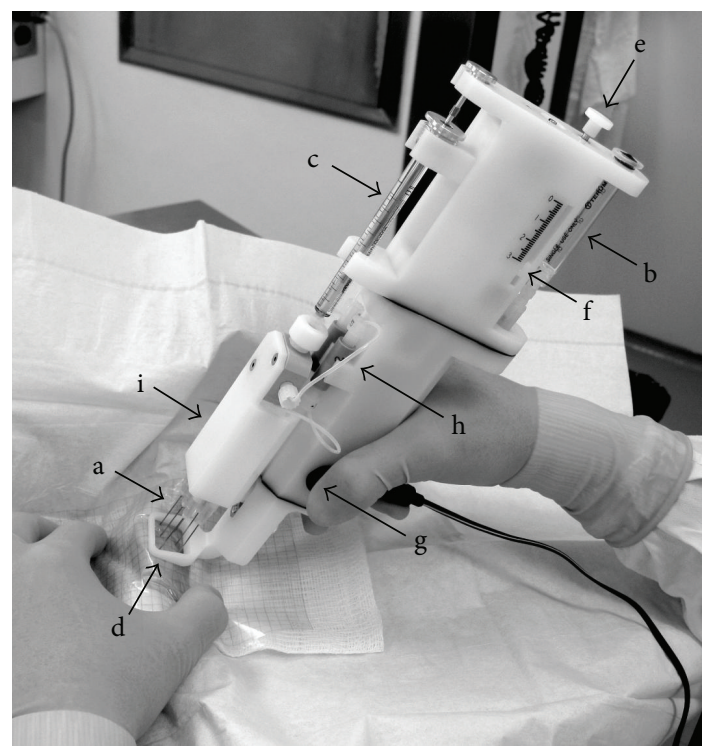

FIGURE 8: First device designed for the percutaneous transplantation of cells by a "high density injection" protocol, shown during transplantation in a nonhuman primate. This prototype delivers very small quantities of cell suspension throughout up to 6 standard disposable needles (a), from a container incorporated to the device (b). From this container, the cell suspension circulates towards the injection needles during the up and down movements of a precision syringe (c). To deliver the cells only in a muscle region and not in the skin and hypodermis, the operator can set the adjustable foot (d) to leave the needle length necessary to go through the skin and hypodermis (estimated by ultrasound analysis). The amplitude of the needles excursion into the muscle can be set between 0 and $3.5 \mathrm{~cm}$ by turning a knob (e), using the indicator of injection depth as a reference (f). The operator introduces then the needles until the foot touches the skin surface (d). At that moment, the needles tips should be at the muscle surface. Pressing a pushbutton (g), the needles penetrate the muscle, and the precision syringe (c) is filled with cell suspension. Once the needles reach the depth of injection set in (f), they are automatically retracted to their original position. The cells are homogeneously delivered in the needles trajectory during this retraction. The operator withdraws the needles and restarts the sequence in another position. Two valves $(\mathrm{h})$ control the appropriate direction of circulation of the cell suspension. Container, syringe, and needles are linked by a plastic support (i) that includes the flow divisor. An electromechanical system into the device's body governs the injection sequence.

(this is the case in most of them) or was studied only very partially, as is the case for MDSCs derived by preplating [110]. In our experience with monkey cells, the overall survival of the transplanted cell population is far better for myoblasts than for pericytes (unpublished observations).

The fact that grafted myoblasts undergo considerable mortality within the first days after their intramuscular transplantation was inferred from the posttransplantation loss of the different markers used to quantify the myoblasts in mice [110, 147-151] and pigs [69]. Additionally, we reported morphological evidence of apoptosis (by immunodetection of active caspase 3) and necrosis (by histochemical detection of intracellular calcium deposition) among mouse myoblasts implanted into mice, during this early post-transplantation period [151]. Active caspase 3 was also reported in human myoblasts transplanted into immunodeficient mice [152].

It is important to keep in mind that although a large part of myoblasts seems to die after transplantation, a part of grafted myoblasts always survives $[69,150,151]$. Whatever the factor that produces the early death of the grafted myoblasts, it never affects all the grafted cells. Moreover, when mouse myoblasts are injected into mice, the proliferation of the surviving cells is always present and compensates either partially [150] or totally [151] the cell death. The differences between the partial or total compensation of the cell death by the proliferation of the surviving cells can be attributed to differences in the result interpretation according to the study [151]. A research group raised the hypothesis that the survival of the myoblast graft is due to a minor subpopulation of cells with specific capacities to evade the early cell death and to proliferate to a great extent $[150,153]$. Although this hypothesis leaves unanswered the cause of the cell death, it was the only one that takes into consideration the curious fact that, even if one or more of the factors mentioned below could indiscriminately kill the grafted cells, the whole grafted-cell population is never eliminated.

It must be remarked that an error of some former studies in this subject was to deduce that a large percentage of cells ( $80 \%$ to $90 \%$ ) died almost immediately after transplantation $[154,155]$. Later, it was confirmed that this was not so, and that in fact it was impossible to detect cell death so fast by the methods used [156]. It remains that some authors have deduced that $60 \%$ of the cells die in the fist hour posttransplantation [150], but two other studies, using similar methods to quantify the grafted cells, did not detect any decrease in the grafted cell population during the same period $[151,156]$.

Initial studies in mice blamed the acute inflammation response for killing most of the grafted myoblasts $[149,157]$. However, this was based on indirect evidence. A study in which specific depletion of immunological cells was done in mice, however, did not find evidence that macrophages or natural killer cells were responsible of reducing the whole population of grafted cells and showed a small but not determinant potential effect of neutrophils in the first days post-transplantation [156]. On the contrary, there was evidence that macrophages can be beneficial for the transplanted myoblasts in mice, improving their survival, proliferation, and migration [158]. Natural killer cell infiltration was in fact very scarce after myoblast transplantation in mice to play a role in the death of the grafted myoblasts [159]. Other causes suggested to induce apoptosis of the grafted myoblasts were hypoxia [141] and anoikis [160]. However, experiments trying to control each of the previous factors in mice never prevented the whole cell death, and only minimal enhancements of survival were reported [152, 161164]. An exception was the administration of an anti-LFA1 antibody in mice, using transgenic $\beta$-galactosidase to label the grafted cells [149]. However, in this experiment immortal cells were used, which have a death and survival dynamics different from cells derived from primary cultures [151, 159]. The diversity of treatments tested, the different methods used 


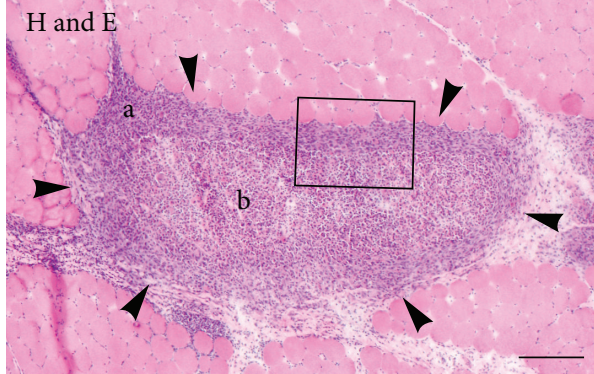

(A)

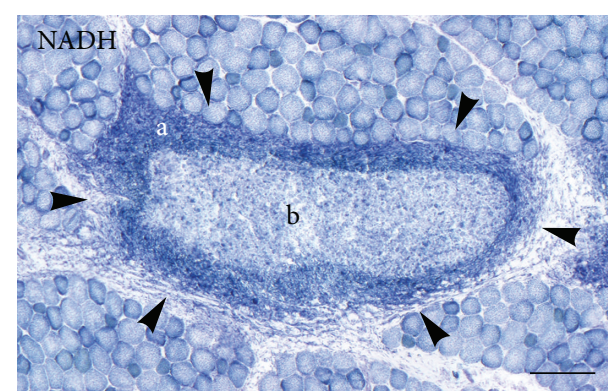

(B)

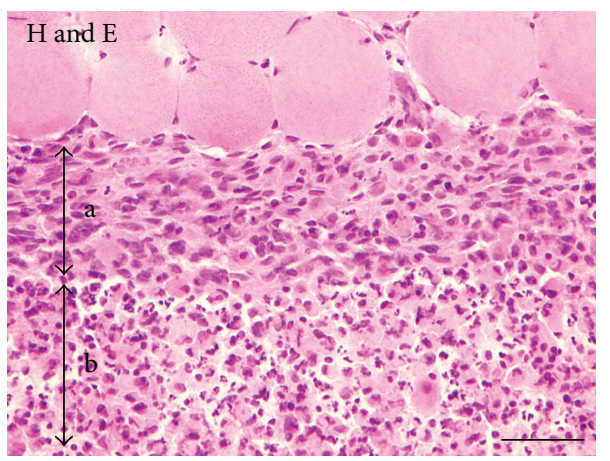

(C)

FIGURE 9: Ischemic necrosis in an intramuscular accumulation of grafted myoblasts one day after their transplantation in the skeletal muscle of a nonhuman primate. Arrowheads in (A) circumscribe the intramuscular accumulation of grafted cells in a section stained with hematoxylin and eosin ( $\mathrm{H}$ and $\mathrm{E})$. Two regions with different staining characteristics can be observed in this cell pocket: a darker peripheral ring (a) and a paler core (b). In a serial section (B) stained for the histochemical detection of the oxidative enzyme nicotinamide adenine dinucleotide reduced diaphorase $(\mathrm{NADH})$, the two regions are more clearly delimitated: a peripheral ring strongly stained ((a): living cells with oxidative activity) and a central region almost devoid of oxidative reaction ((b): necrosed cells with few or no oxidative activity). A detail of this pocket of grafted cells (rectangle in (A)) is shown at higher magnification in (C). In (C), the peripheral layer (a) is composed of cells with normal characteristics, while the core (b) has smaller cells with pyknosis, karyorrhexis, and in several cases loss of cytoplasmic staining. Scale bars: $200 \mu \mathrm{m}((\mathrm{A})$ and $(\mathrm{B}))$ and $50 \mu \mathrm{m}(\mathrm{C})$.

to quantify the population of grafted cells, and the fact that the reduction of cell death was generally minimal complicate the analysis of the subject. Despite the studies carried-out to date, this process of cell death and proliferation after transplantation is still not well understood.

A specific mechanism of cell death that was morphologically and unambiguously detected by the author after intramuscular cell transplantation in nonhuman primates is the ischemic necrosis of the inner region of the accumulations of injected cells [165]. Since the implanted cells form avascular collections whose survival depends on the limited diffusion of oxygen and nutrients from the surrounding tissue, only a peripheral layer of around $100-200 \mu \mathrm{m}$ survives the first hours post-transplantation (Figure 9). The amount of ischemic necrosis depends on the form and size of the collection of grafted cells. This allows to simply reduce the central ischemic death by using transplantation strategies avoiding to form too large cell collections [165]. This is an important factor to be considered in clinical applications, to avoid falling into the temptation to inject large amounts of cells in only one place with the intention of regenerating tissue.

\subsection{The Long-Term Survival of the Myogenic Cell Graft}

Acute Rejection. Acute rejection seems to be the only factor that compromises the long-term survival of the myogeniccell graft. Acute rejection is the mechanism by which donoralloantigen-reactive cytolytic T-lymphocytes of the recipient destroy an allograft by a response implicating recognition of the MHC class I on the donor cells. Although MHC class I is not present on normal mature myofibers [166168], its expression was observed during muscle regeneration, inflammatory myopathies, and in DMD [167-169]. In addition, myoblasts and myotubes express MHC class I [170-172]. Fortunately, acute rejection is not an insurmountable obstacle for the transplantation of organs, composite tissues, and even for transplantation of cells such as islets in the treatment of severe diabetes.

In what should be considered the first report of acute rejection in myogenic cell transplantation, Jones described in 1979 that the loss of the myoblast graft in allogeneic conditions was accompanied by lymphocyte infiltration [173]. Posterior reports identified CD8+ and CD4+ cells in lymphocyte infiltrates occurring during rejection of myoblast 
transplantation in mice [174-176]. Expression of IL-2 receptors, Th-1 cytokine, and granzyme B confirmed that these were activated lymphocytes $[177,178]$. Invasion of myofibers by CD8+ cells, that is considered a sign of T-lymphocyte mediated toxicity in muscle, was reported in mice [175]. It was even suggested that this lymphocytic attack not only rejects the hybrid myofibers resulting from the cell transplantation, but also can damage the host myofibers by the "bystander" effect of released cytokines [176]. Incompatibility in minor antigens can also trigger acute rejection of hybrid myofibers, as observed in mice after syngeneic transplantation into females of myoblasts obtained from males [179].

Observations in mice were not very useful to aid in the diagnosis of acute rejection in our last clinical trials of myoblast transplantation. For that specific purpose, the author conducted a study in nonhuman primates to define the histological features of acute rejection of hybrid myofibers [180]. Independent on the way to induce acute rejection of the hybrid myofibers (withdrawal of immunosuppression, low immunosuppression or progressive reduction of immunosuppression) and on the post-transplantation period in which rejection occurs, the histological presentation of this phenomenon followed a stereotyped pattern [180]. The graft loss was associated in all cases to myositis characterized by the presence of dense focal accumulations of CD8+ and CD4+ lymphocytes and a more diffuse component of macrophages. Typically, these lymphocyte accumulations were mainly endomysial, totally or partially surrounded some myofibers, and often invaded them. The similarity with some observations in humans [11] confirmed the usefulness of these results for the histological diagnosis of acute rejection in clinical trials of myogenic cell transplantation. We also identified some mechanisms by which the hybrid myofibers are eliminated by the immune system [181]. There was evidence of sarcolemmal damage in the myofiber regions invaded by lymphocytes, together with evidence of myofiber necrosis during the rejection process [181]. We also observed that caspase 3 is activated at least in some of the myofibers attacked by CD8+ lymphocytes, but we did not find evidence of a complete classical process of apoptosis in these myofibers [181].

Control of Acute Rejection: Immunosuppression. On the contrary of the early cell death, acute rejection, if not controlled, eliminates all the transplanted cells and hybrid myofibers and thus prevents the success of myogenic cell transplantation. Nevertheless, acute rejection is a well-defined factor and there is an efficient approach to control it, that is, pharmacological immunosuppression. However, the choice of the immunosuppressive drugs is yet more relevant than in the case of organ transplants, as the drug can affect the survival or behavior of the transplanted cells or affect the pathways that are necessary for an efficient engraftment. An example is cyclophosphamide, which was tested as immunosuppressant for myoblast transplantation in mice and gave negative results [182]. Given that it is an antiproliferative drug, it was suggested that cyclophosphamide kills the transplanted cells as soon as they proliferate [182]. Cyclosporine A was effective for the engraftment of myoblasts in some mouse experiments
$[21,175,183,184]$. However, cyclosporine inhibited myoblast fusion in vitro at therapeutic doses [185], blocked myoblast differentiation [186], and induced apoptosis in these cells [186], properties that could be detrimental for myogenic cell transplantation. Mycophenolate mofetil alone did not lead to myoblast transplantation success in mice and inhibited myoblast fusion in vitro [187]. In mouse experiments, mycophenolate mofetil combined to tacrolimus reduced the success of myoblast transplantation [187]. This was not the case in primates [122] although so far this combination seemed not synergic for myoblast transplantation in this model (nonpublished observations). Sirolimus was effective in allowing good myoblast transplantation results in mice [139] and in one study it was more effective than cyclosporine to control the humoral response after myoblast transplantation [188]. In mice, control of acute rejection in myoblast transplantation experiments (for short periods) was also observed with monoclonal antibodies directed against lymphocyte adhesion molecules (CD4, CD8 and LFA-1) and using CTLA4-Ig combined with an anti-CD4 [183, 189].

Optimal myoblast engraftments in mice were obtained using tacrolimus for immunosuppression [9]. Given the good results obtained later in macaques, tacrolimus monotherapy becomes our routine immunosuppression for myoblast allotransplantation studies in nonhuman primates [120-123, $143,180,190,191]$. In this model, we confirmed that hybrid myofibers produced by the engraftment of myoblasts can be maintained in the absence of acute rejection during followups of several months $[121,180]$. We showed that a stronger immunosuppression is needed in the immediate post-transplantation period in nonhuman primates, but that the tacrolimus blood levels can be reduced later and the graft can be maintained as long as the tacrolimus blood levels do not drop below a minimum [180]. However, even tacrolimus could have potential untoward effect for the transplantation of myogenic cells, since calcineurin inhibition (the mechanism of action of tacrolimus and cyclosporine) inhibits skeletal muscle hypertrophy [192].

Given these results in nonhuman primates, the most recent clinical trials of myoblast transplantation carried out by our research group were done under tacrolimus monotherapy [11-13]. The first of them showed hybrid myofibers expressing donor-derived dystrophin in 8 of 9 DMD patients, but the followup was for only one month [11, 13]. Afterwards, we were able to perform a followup of 18 months following transplantation of normal myoblasts in an adult DMD patient, and we detected donorderived dystrophin 1 month post-transplantation $(27.5 \%$ of the myofibers were donor-dystrophin+) and 18 months post-transplantation $(34.5 \%$ of the myofibers were donordystrophin+) [12]. This case was the first confirmation that a good control of acute rejection can maintain the hybrid myofibers for long periods in humans.

Experimental Strategies to Avoid Acute Rejection: Immune Tolerance. Given that any chronic immunosuppression exposes the patients to the risks of moderate to severe side effects, a major research in transplantation is addressed to the development specific immune tolerance [193]. The objective 
of this research is to obtain long-term unresponsiveness to the graft preserving the immune capacity of the recipient to combat pathogens and to eliminate cancer cells. This is a major goal in the global field of transplantation, and myogenic cell transplantation will be subsidiary for the progress in this research. Currently, there is no protocol for induction of tolerance regularly applicable in humans. Our team has specifically tried some protocols to induce tolerance for myoblast allotransplantation in mice. Central tolerance via mixed chimerism $[194,195]$ was superior to antiCD154 administration and donor-specific transfusion [196]. Nevertheless, central tolerance in the context of myogeniccell allotransplantation would not include neoantigens in the hybrid myofibers and would need also peripheral tolerance [197]. These experiences must take into account the difficulties involved on transferring to human tolerance protocols achieved in mice. On one hand, it is much easier to develop immunological tolerance in mice. On the other hand, in several cases tolerance in mice is considered successful even if it lasts for only few months, while tolerance in humans must persist for years and even decades. An example of the problem of using mice for these experiments was a previous observation that a transient immunosuppression allowed immune tolerance to myoblast grafts in some mouse strains [183]. This may be erroneously taken as a proof that tolerance is easily obtainable in myoblast transplantation. However, tolerance was not observed in other mouse strains in the same conditions [21, 183]. Importantly, acute rejection of hybrid myofibers always occur in nonhuman primates following transient immunosuppression, regardless if it lasts for months and is decreased slowly $[121,180,181]$.

Experimental Strategies to Avoid Acute Rejection: Autotransplantation of Cells Genetically Corrected Ex Vivo (Figure 10). Because cells can be manipulated in culture before implantation, cell transplantation provides specific possibilities to try to avoid immunosuppression. The classical example is the autotransplantation of cells genetically corrected ex vivo, for example, by introducing the gene of dystrophin in DMD cells [198]. This strategy avoids incompatibility of the Major Histocompatibility Complex among the recipient and the transplanted mononuclear cells, but leaves the possibility of eliciting a specific immune response if the genetically-modified cells express epitopes not shared with the recipient [199]. Since the first experiments that used adenoviral vectors [200202], the range of possibilities of genetic manipulation of the cells has been growing. Among viral vectors, lentiviruses attract much attention because they can infect postmitotic or quiescent cells and integrate the transgene in the host genome, providing stable long-term gene expression both in vitro and in vivo $[203,204]$. The problem of lentiviruses is however that they can carry a relatively small gene [205], and that there is the risk of insertional mutagenesis [206]. Several nonviral techniques were also tested in this sense. Transposons have the capacity of stable integration of genes into the genome and high gene expression level over long period of time [207]. An exciting avenue is the use of artificial chromosomes to genetically correct the cells [208]. Artificial

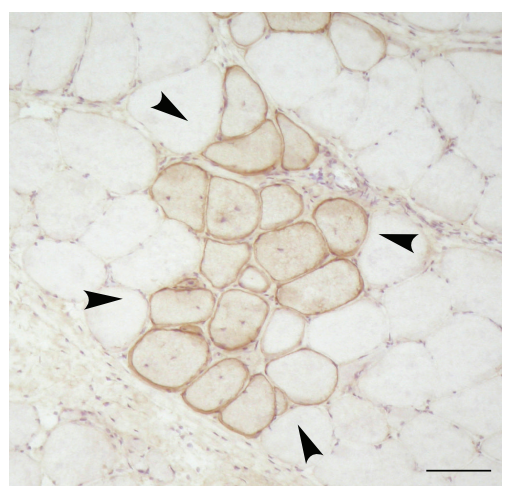

FIGURE 10: Autotransplantation of myoblasts genetically modified ex vivo in a nonhuman primate. Myoblasts were grown in vitro from a biopsy performed in a skeletal muscle of a cynomolgus monkey. The cells were infected in vitro with a lentivirus containing a cassette including a microdystrophin coupled to a V5 peptide tag. These myoblasts were intramuscularly injected in the same monkey, in the absence of immunosuppression, and the injected site was sampled 1 month later. The figure shows a transversal section of the biopsy of the cell-grafted region. The V5 fusion protein was detected by peroxidase immunodetection with an anti-V 5 antibody counterstained with diluted hematoxylin. Myofibers expressing the V5-tagged micro-dystrophin are shown between arrowheads. The labeling is essentially sarcoplasmic, according to the normal location of dystrophin, although some intracellular pale staining is also observed. Some of the V5-positive myofibers exhibit internal nuclei, indicating recent regeneration. This is in agreement to the fact that the grafted cells participated in the regeneration of myofibers damaged by the injection needle. Without immunosuppression and in allogeneic conditions, these myofibers would be already rejected. In this case, not only the hybrid myofibers are still present after 1 month, but also there is no histological evidence of acute rejection (i.e., no lymphocyte accumulations around the hybrid myofibers). Scale bar $=100 \mu \mathrm{m}$.

chromosomes have the advantages of avoiding insertional mutagenesis and lodging the full-length dystrophin gene with its regulatory elements [209]. Human artificial chromosomes were already used to introduce the full length dystrophin gene into induced pluripotent stem cells derived from DMD patients [210]. A first experiment of transplantation in mice of myogenic cells corrected with the same strategy was done with mesoangioblasts [211].

A problem of using satellite cells and myoblasts for strategies of autotransplantation is the reduced proliferative capacity of these cells in DMD patients [212]. Some possibilities studied to avoid this problem were to immortalize the DMD myoblasts with the thermolabile tsA58 mutant of SV40 large-T antigen [213] or by genetically restoring the telomerase activity $[214,215]$. One possibility to circumvent this problem would be to use some of the myogenic cells described above as "heterodox," provided that these other cells can be efficient for transplantation in humans. Some studies raised the possibility of transdifferentiate other cells into muscle-precursor cells. The potential use of fibroblasts to produce myogenic cells would have advantages such as a less invasive procedure to obtain cells, culture in low medium requirements, and proliferation in vitro without fusion into 
myotubes. This transdifferentiation was obtained for example by transducing fibroblasts with MyoD1, a master regulator gene for myogenesis, although the transplantation efficiency of these cells was significantly reduced [216]. Galectin-1, a lectin secreted by myoblasts and myotubes in culture, was reported to convert $100 \%$ of dermal fibroblasts (although no muscle-derived fibroblasts) into myoblasts [217, 218]. Presently, probably the most interesting avenue to obtain autologous myogenic cells not hampered by senescence are induced pluripotent stem cells. Induced pluripotent stem cells are pluripotent cells with properties similar to embryonic stem cells obtained by reprogramming somatic cells such as fibroblasts $[219,220]$. In this sense, there were already experiences that demonstrated the possibility of producing myoblasts from induced pluripotent stem cells obtained from mice [221-224] and humans [225].

\section{Conclusions}

There are some crucial challenges in order to facilitate the clinical applicability of cell transplantation in the treatment of myopathies. To obtain a therapeutic level of gene complementation, we need to expand the cell engraftment to significant levels while, at the same time, reducing as much as possible the complications inherent to the protocol of cell delivery. On the other hand, if we want to treat the advanced stages of the disease, we need to clarify the factors that could contribute to form new functional myofibers in muscles replaced by fibrosis and fat tissue. Finally, we need to avoid or at least to reduce the toxicity of the approaches to control acute rejection.

To the moment of writing this review, even if with technical constraints that need to be solved, improved, and instrumentalized, the only myogenic cells that were proved unequivocally to engraft in humans were adult myoblasts [10-13]. The other cases in which other potentially myogenic cells were studied or are being studied in humans, either gave negative results, as bone marrow derived cells [90, 91], or were not used in conditions that allowed assessing the engraftment, as CD133+ cells [109], or the results are still being awaited, as is the case of mesoangioblasts [99]. The main lesson of the saga of clinical trials of myoblast transplantation is that certain crucial elements, such as the adequate control of acute rejection and the quantitative definition of the injection parameters, must be well defined in appropriate animal models before being applied to humans. Otherwise, we run the risk of improvising the transplantation according to our wishes, and the chances of failure and frustration are high.

\section{Acknowledgments}

The author wishes to express his gratitude to Dr. Jacques P. Tremblay for the opportunity to be a part of his research team, in which he freely conducted experiments in nonhuman primates and developed the method of transplantation that was later applied in patients.

\section{References}

[1] Y. Ishikawa, T. Miura, Y. Ishikawa et al., "Duchenne muscular dystrophy: survival by cardio-respiratory interventions," $\mathrm{Neu}$ romuscular Disorders, vol. 21, no. 1, pp. 47-51, 2011.

[2] J. D. Gumerson and D. E. Michele, "The dystrophinglycoprotein complex in the prevention of muscle damage," Journal of Biomedicine and Biotechnology, vol. 2011, Article ID 210797, 13 pages, 2011.

[3] D. Skuk, M. Goulet, and J. P. Tremblay, "Preservation of muscle spindles in a 27-year-old Duchenne muscular dystrophy patient: importance for regenerative medicine strategies," Muscle \& Nerve, vol. 41, no. 5, pp. 729-730, 2010.

[4] B. H. Lipton and E. Schultz, "Developmental fate of skeletal muscle satellite cells," Science, vol. 205, no. 4412, pp. 1292-1294, 1979.

[5] D. J. Watt, K. Lambert, and J. E. Morgan, "Incorporation of donor muscle precursor cells into an area of muscle regeneration in the host mouse," Journal of the Neurological Sciences, vol. 57, no. 2-3, pp. 319-331, 1982.

[6] D. Yaffe and M. Feldman, "The formation of hybrid multinucleated muscle fibers from myoblasts of different genetic origin," Developmental Biology, vol. 11, no. 2, pp. 300-317, 1965.

[7] T. A. Partridge, J. E. Morgan, G. R. Coulton, E. P. Hoffman, and L. M. Kunkel, "Conversion of mdx myofibres from dystrophinnegative to -positive by injection of normal myoblasts," Nature, vol. 337, no. 6203, pp. 176-179, 1989.

[8] G. Karpati, Y. Pouliot, E. Zubrzycka-Gaarn et al., "Dystrophin is expressed in mdx skeletal muscle fibers after normal myoblast implantation," American Journal of Pathology, vol. 135, no. 1, pp. 27-32, 1989.

[9] I. Kinoshita, J.-T. Vilquin, B. Guerette, I. Asselin, R. Roy, and J. P. Tremblay, "Very efficient myoblast allotransplantation in mice under FK506 immunosuppression," Muscle \& Nerve, vol. 17, no. 12, pp. 1407-1415, 1994.

[10] J. R. Mendell, J. T. Kissel, A. A. Amato et al., "Myoblast transfer in the treatment of Duchenne's muscular dystrophy," New England Journal of Medicine, vol. 333, no. 13, pp. 832-838, 1995.

[11] D. Skuk, M. Goulet, B. Roy et al., "Dystrophin expression in muscles of Duchenne muscular dystrophy patients after high-density injections of normal myogenic cells," Journal of Neuropathology and Experimental Neurology, vol. 65, no. 4, pp. 371-386, 2006.

[12] D. Skuk, M. Goulet, B. Roy et al., "First test of a "highdensity injection" protocol for myogenic cell transplantation throughout large volumes of muscles in a Duchenne muscular dystrophy patient: eighteen months follow-up," Neuromuscular Disorders, vol. 17, no. 1, pp. 38-46, 2007.

[13] D. Skuk, B. Roy, M. Goulet et al., "Dystrophin expression in myofibers of Duchenne muscular dystrophy patients following intramuscular injections of normal myogenic cells," Molecular Therapy, vol. 9, no. 3, pp. 475-482, 2004.

[14] G. K. Pavlath, K. Rich, S. G. Webster, and H. M. Blau, "Localization of muscle gene products in nuclear domains," Nature, vol. 337, no. 6207, pp. 570-573, 1989.

[15] E. Ralston and Z. W. Hall, "Restricted distribution of mRNA produced from a single nucleus in hybrid myotubes," Journal of Cell Biology, vol. 119, no. 5, pp. 1063-1068, 1992.

[16] Z. W. Hall and E. Ralston, "Nuclear domains in muscle cells," Cell, vol. 59, no. 5, pp. 771-772, 1989. 
[17] F. Chretien, P. A. Dreyfus, C. Christov et al., "In vivo fusion of circulating fluorescent cells with dystrophin-deficient myofibers results in extensive sarcoplasmic fluorescence expression but limited dystrophin sarcolemmal expression," American Journal of Pathology, vol. 166, no. 6, pp. 1741-1748, 2005.

[18] E. Gussoni, H. M. Blau, and L. M. Kunkel, "The fate of individual myoblasts after transplantation into muscles of DMD patients," Nature Medicine, vol. 3, no. 9, pp. 970-974, 1997.

[19] H. S. Alameddine, J. P. Louboutin, M. Dehaupas, A. Sebille, and M. Fardeau, "Functional recovery induced by satellite cell grafts in irreversibly injured muscles," Cell Transplantation, vol. 3, no. 1, pp. 3-14, 1994.

[20] A. Wernig, M. Zweyer, and A. Irintchev, "Function of skeletal muscle tissue formed after myoblast transplantation into irradiated mouse muscles," Journal of Physiology, vol. 522, no. 2, pp. 333-345, 2000.

[21] A. Wernig, A. Irintchev, and G. Lange, "Functional effects of myoblast implantation into histoincompatible mice with or without immunosuppression," Journal of Physiology, vol. 484, no. 2, pp. 493-504, 1995.

[22] A. Irintchev, M. Langer, M. Zweyer, R. Theisen, and A. Wernig, "Functional improvement of damaged adult mouse muscle by implantation of primary myoblasts," Journal of Physiology, vol. 500, no. 3, pp. 775-785, 1997.

[23] R. Vracko and E. P. Benditt, "Basal lamina: the scaffold for orderly cell replacement. Observations on regeneration of injured skeletal muscle fibers and capillaries," Journal of Cell Biology, vol. 55, no. 2, pp. 406-419, 1972.

[24] A. Irintchev, J. D. Rosenblatt, M. J. Cullen, M. Zweyer, and A. Wernig, "Ectopic skeletal muscles derived from myoblasts implanted under the skin," Journal of Cell Science, vol. 111, no. 22, pp. 3287-3297, 1998.

[25] I. Kinoshita, J. Vilquin, and J. P. Tremblay, "Mechanism of increasing dystrophin-positive myofibers by myoblast transplantation: study using $\mathrm{mdx} / \beta$-galactosidase transgenic mice," Acta Neuropathologica, vol. 91, no. 5, pp. 489-493, 1996.

[26] A. Satoh, C. Labrecque, and J. P. Tremblay, "Myotubes can be formed within implanted adipose tissue," Transplantation Proceedings, vol. 24, no. 6, pp. 3017-3019, 1992.

[27] D. F. Pisani, C. A. Dechesne, S. Sacconi et al., "Isolation of a highly myogenic CD34-negative subset of human skeletal muscle cells free of adipogenic potential," Stem Cells, vol. 28, no. 4, pp. 753-764, 2010.

[28] Y. Huang, R. G. Dennis, L. Larkin, and K. Baar, "Rapid formation of functional muscle in vitro using fibrin gels," Journal of Applied Physiology, vol. 98, no. 2, pp. 706-713, 2005.

[29] T. Okano and T. Matsuda, "Muscular tissue engineering: capillary-incorporated hybrid muscular tissues in vivo tissue culture," Cell Transplantation, vol. 7, no. 5, pp. 435-442, 1998.

[30] T. Yokota, Q. Lu, J. E. Morgan et al., "Expansion of revertant fibers in dystrophic mdx muscles reflects activity of muscle precursor cells and serves as an index of muscle regeneration," Journal of Cell Science, vol. 119, no. 13, pp. 2679-2687, 2006.

[31] S.-N. Yao and K. Kurachi, "Implanted myoblasts not only fuse with myofibers but also survive as muscle precursor cells," Journal of Cell Science, vol. 105, no. 4, pp. 957-963, 1993.

[32] J. G. Gross and J. E. Morgan, "Muscle precursor cells injected into irradiated mdx mouse muscle persist after serial injury," Muscle \& Nerve, vol. 22, no. 2, pp. 174-185, 1999.
[33] X. Xu, Z. Yang, Q. Liu, and Y. Wang, "In vivo fluorescence imaging of muscle cell regeneration by transplanted EGFPlabeled myoblasts," Molecular Therapy, vol. 18, no. 4, pp. 835$842,2010$.

[34] L. Heslop, J. R. Beauchamp, S. Tajbakhsh, M. E. Buckingham, T. A. Partridge, and P. S. Zammit, "Transplanted primary neonatal myoblasts can give rise to functional satellite cells as identified using the Myf5 $5^{\text {nlacz/+ }}$ mouse," Gene Therapy, vol. 8, no. 10, pp. 778-783, 2001.

[35] D. Skuk, M. Paradis, M. Goulet, P. Chapdelaine, D. M. Rothstein, and J. P. Tremblay, "Intramuscular transplantation of human postnatal myoblasts generates functional donor-derived satellite cells," Molecular Therapy, vol. 18, no. 9, pp. 1689-1697, 2010.

[36] K. Brimah, J. Ehrhardt, V. Mouly, G. S. Butler-Browne, T. A. Partridge, and J. E. Morgan, "Human muscle precursor cell regeneration in the mouse host is enhanced by growth factors," Human Gene Therapy, vol. 15, no. 11, pp. 1109-1124, 2004.

[37] J. Ehrhardt, K. Brimah, C. Adkin, T. Partridge, and J. Morgan, "Human muscle precursor cells give rise to functional satellite cells in vivo," Neuromuscular Disorders, vol. 17, no. 8, pp. 631638, 2007.

[38] E. Negroni, I. Riederer, S. Chaouch et al., "In vivo myogenic potential of human CD133+ muscle-derived stem cells: a quantitative study," Molecular Therapy, vol. 17, no. 10, pp. 1771-1778, 2009.

[39] K. Vauchez, J. Marolleau, M. Schmid et al., "Aldehyde dehydrogenase activity identifies a population of human skeletal muscle cells with high myogenic capacities," Molecular Therapy, vol. 17, no. 11, pp. 1948-1958, 2009.

[40] A. Dellavalle, M. Sampaolesi, R. Tonlorenzi et al., "Pericytes of human skeletal muscle are myogenic precursors distinct from satellite cells," Nature Cell Biology, vol. 9, no. 3, pp. 255-267, 2007.

[41] D. Montarras, J. Morgan, C. Colins et al., "Developmental biology: direct isolation of satellite cells for skeletal muscle regeneration," Science, vol. 309, no. 5743, pp. 2064-2067, 2005.

[42] T. A. Partridge, M. Grounds, and J. C. Sloper, "Evidence of fusion between host and donor myoblasts in skeletal muscle grafts," Nature, vol. 273, no. 5660, pp. 306-308, 1978.

[43] P. S. Zammit, L. Heslop, V. Hudon et al., "Kinetics of myoblast proliferation show that resident satellite cells are competent to fully regenerate skeletal muscle fibers," Experimental Cell Research, vol. 281, no. 1, pp. 39-49, 2002.

[44] R. Sambasivan, R. Yao, A. Kissenpfennig et al., "Pax7-expressing satellite cells are indispensable for adult skeletal muscle regeneration," Development, vol. 138, no. 17, pp. 3647-3656, 2011.

[45] C. Lepper, T. A. Partridge, and C. Fan, "An absolute requirement for pax7-positive satellite cells in acute injury-induced skeletal muscle regeneration," Development, vol. 138, no. 17, pp. 36393646, 2011.

[46] M. M. Murphy, J. A. Lawson, S. J. Mathew, D. A. Hutcheson, and G. Kardon, "Satellite cells, connective tissue fibroblasts and their interactions are crucial for muscle regeneration," Development, vol. 138, no. 17, pp. 3625-3637, 2011.

[47] M. R. Lewis, "Rhythmical contraction of the skeletal muscle tissue observed in tissue culture," American Journal of Physiology, vol. 38, pp. 153-161, 1915.

[48] Z. Yablonka-Reuveni and M. Nameroff, "Temporal differences in desmin expression between myoblasts from embryonic and adult chicken skeletal muscle," Differentiation, vol. 45, no. 1, pp. 21-28, 1990. 
[49] J. Wang and I. Conboy, "Embryonic vs. adult myogenesis: challenging the "regeneration recapitulates development" paradigm," Journal of Molecular Cell Biology, vol. 2, no. 1, pp. $1-4,2010$.

[50] C. Lepper, S. J. Conway, and C. Fan, "Adult satellite cells and embryonic muscle progenitors have distinct genetic requirements," Nature, vol. 460, no. 7255, pp. 627-631, 2009.

[51] G. Cossu and M. Molinaro, "Chapter 9 cell heterogeneity in the myogenic lineage," Current Topics in Developmental Biology C, vol. 23, pp. 185-208, 1987.

[52] A. Mauro, "Satellite cell of skeletal muscle fibers," The Journal of Biophysical and Biochemical Cytology, vol. 9, pp. 493-495, 1961.

[53] B. M. Carlson, "Muscle regeneration in amphibians and mammals: passing the torch," Developmental Dynamics, vol. 226, no. 2, pp. 167-181, 2003.

[54] S. B. Charge and M. A. Rudnicki, "Cellular and molecular regulation of muscle regeneration," Physiological Reviews, vol. 84, no. 1, pp. 209-238, 2004.

[55] R. N. Cooper, S. Tajbakhsh, V. Mouly, G. Cossu, M. Buckingham, and G. S. Butler-Browne, "In vivo satellite cell activation via Myf5 and MyoD in regenerating mouse skeletal muscle," Journal of Cell Science, vol. 112, no. 17, pp. 2895-2901, 1999.

[56] Z. Yablonka-Reuveni and A. J. Rivera, "Temporal expression of regulatory and structural muscle proteins during myogenesis of satellite cells on isolated adult rat fibers," Developmental Biology, vol. 164, no. 2, pp. 588-603, 1994.

[57] P. S. Zammit, J. P. Golding, Y. Nagata, V. Hudon, T. A. Partridge, and J. R. Beauchamp, "Muscle satellite cells adopt divergent fates: a mechanism for self-renewal?" Journal of Cell Biology, vol. 166, no. 3, pp. 347-357, 2004.

[58] C. A. Collins, I. Olsen, P. S. Zammit et al., "Stem cell function, self-renewal, and behavioral heterogeneity of cells from the adult muscle satellite cell niche," Cell, vol. 122, no. 2, pp. 289301, 2005.

[59] I. R. Konigsberg, "The differentiation of cross-striated myofibrils in short term cell culture," Experimental Cell Research, vol. 21, no. 2, pp. 414-420, 1960.

[60] J. T. Vilquin, J.-P. Marolleau, A. Hagege, P. Menasche, M. Fiszman, and K. Schwartz, "Cell transplantation for postischemic heart failure," Archives des Maladies du Coeur et des Vaisseaux, vol. 95, no. 12, pp. 1219-1225, 2002.

[61] D. Skuk and J. P. Tremblay, "Myoblast transplantation: the current status of a potential therapeutic tool for myopathies," Journal of Muscle Research and Cell Motility, vol. 24, no. 4-6, pp. 285-300, 2003.

[62] C. L. Pin and P. A. Merrifield, "Developmental potential of rat L6 myoblasts in vivo following injection into regenerating muscles," Developmental Biology, vol. 188, no. 1, pp. 147-166, 1997.

[63] M. Cantini, M. L. Massimino, C. Catani, R. Rizzuto, M. Brini, and U. Carraro, "Gene transfer into satellite cell from regenerating muscle: bupivacaine allows $\beta$-gal transfection and expression in vitro and in vivo," In Vitro Cellular and Developmental Biology-Animal, vol. 30, no. 2, pp. 131-133, 1994.

[64] J. N. Kornegay, S. M. Prattis, D. J. Bogan et al., "Results of myoblast transplantation in a canine model of muscle injury," in Duchenne Muscular Dystrophy: Animal Models and Genetic Manipulation, pp. 203-212, Raven Press, New York, NY, USA, 1992.

[65] H. Ito, J. Vilquin, D. Skuk et al., "Myoblast transplantation in non-dystrophic dog," Neuromuscular Disorders, vol. 8, no. 2, pp. 95-110, 1998.
[66] D. Skuk, M. Goulet, M. Paradis, and J. P. Tremblay, "Myoblast transplantation: techniques in nonhuman primates as a bridge to clinical trials," in Methods in BioengIneerIng: Cell Transplantation, pp. 219-236, Artech House, Boston, Mass, USA, 2011.

[67] B. Coulet, F. Lacombe, C. Lazerges et al., "Short- or long-term effects of adult myoblast transfer on properties of reinnervated skeletal muscles," Muscle \& Nerve, vol. 33, no. 2, pp. 254-264, 2006.

[68] M. César, S. Roussanne-Domergue, B. Coulet et al., “Transplantation of adult myoblasts or adipose tissue precursor cells by high-density injection failed to improve reinnervated skeletal muscles," Muscle \& Nerve, vol. 37, no. 2, pp. 219-230, 2008.

[69] N. Holzer, S. Hogendoorn, L. Zürcher et al., "Autologous transplantation of porcine myogenic precursor cells in skeletal muscle," Neuromuscular Disorders, vol. 15, no. 3, pp. 237-244, 2005.

[70] Z. Qu-Petersen, B. Deasy, R. Jankowski et al., "Identification of a novel population of muscle stem cells in mice: potential for muscle regeneration," Journal of Cell Biology, vol. 157, no. 5, pp. 851-864, 2002.

[71] M. Sampaolesi, Y. Torrente, A. Innocenzi et al., "Cell therapy of $\alpha$-sarcoglycan null dystrophic mice through intra-arterial delivery of mesoangioblasts," Science, vol. 301, no. 5632, pp. 487492, 2003.

[72] M. Sampaolesi, S. Blot, G. D’Antona et al., "Mesoangioblast stem cells ameliorate muscle function in dystrophic dogs," Nature, vol. 444, no. 7119, pp. 574-579, 2006.

[73] M. Crisan, S. Yap, L. Casteilla et al., "A perivascular origin for mesenchymal stem cells in multiple human organs," Cell Stem Cell, vol. 3, no. 3, pp. 301-313, 2008.

[74] B. Zheng, B. Cao, M. Crisan et al., "Prospective identification of myogenic endothelial cells in human skeletal muscle," Nature Biotechnology, vol. 25, no. 9, pp. 1025-1034, 2007.

[75] R. Benchaouir, M. Meregalli, A. Farini et al., "Restoration of human dystrophin following transplantation of exon-skippingengineered DMD patient stem cells into dystrophic mice," Cell Stem Cell, vol. 1, no. 6, pp. 646-657, 2007.

[76] K. J. Mitchell, A. Pannérec, B. Cadot et al., "Identification and characterization of a non-satellite cell muscle resident progenitor during postnatal development," Nature Cell Biology, vol. 12, no. 3, pp. 257-266, 2010.

[77] K. Liadaki, J. C. Casar, M. Wessen et al., "Beta4 integrin marks interstitial myogenic progenitor cells in adult murine skeletal muscle," Journal of Histochemistry and Cytochemistry, vol. 60, no. 1, pp. 31-44, 2012.

[78] A. Pannerec, G. Marazzi, and D. Sassoon, "Stem cells in the hood: the skeletal muscle niche," Trends in Molecular Medicine, vol. 18, no. 10, pp. 599-606, 2012.

[79] M. D. Grounds, "Skeletal muscle precursors do not arise from bone marrow cells," Cell and Tissue Research, vol. 234, no. 3, pp. 713-722, 1983.

[80] E. Schultz, D. L. Jaryszak, M. C. Gibson, and D. J. Albright, "Absence of exogenous satellite cell contribution to regeneration of frozen skeletal muscle," Journal of Muscle Research and Cell Motility, vol. 7, no. 4, pp. 361-367, 1986.

[81] S. Wakeford, D. J. Watt, and T. A. Partridge, "X-irradiation improves mdx mouse muscle as a model of myofiber loss in DMD," Muscle \& Nerve, vol. 14, no. 1, pp. 42-50, 1990.

[82] B. Weller, G. Karpati, S. Lehnert, S. Carpenter, B. Ajdukovic, and P. Holland, "Inhibition of myosatellite cell proliferation by gamma irradiation does not prevent the age-related increase of 
the number of dystrophin-positive fibers in soleus muscles of mdx female heterozygote mice," American Journal of Pathology, vol. 138, no. 6, pp. 1497-1502, 1991.

[83] J. D. Rosenblatt and D. J. Parry, "Gamma irradiation prevents compensatory hypertrophy of overloaded mouse extensor digitorum longus muscle," Journal of Applied Physiology, vol. 73, no. 6, pp. 2538-2543, 1992.

[84] T. A. Robertson, M. D. Grounds, and J. M. Papadimitriou, "Elucidation of aspects of murine skeletal muscle regeneration using local and whole body irradiation," Journal of Anatomy, vol. 181, no. 2, pp. 265-276, 1992.

[85] G. Ferrari, G. Cusella-De Angelis, M. Coletta et al., "Muscle regeneration by bone marrow-derived myogenic progenitors," Science, vol. 279, no. 5356, pp. 1528-1530, 1998.

[86] E. Gussoni, Y. Soneoka, C. D. Strickland et al., "Dystrophin expression in the mdx mouse restored by stem cell transplantation," Nature, vol. 401, no. 6751, pp. 390-394, 1999.

[87] G. Ferrari, A. Stornaiuolo, and F. Mavilio, "Failure to correct murine muscular dystrophy," Nature, vol. 411, no. 6841, pp. 10141015, 2001.

[88] S. Corti, S. Strazzer, R. Del Bo et al., "A subpopulation of murine bone marrow cells fully differentiates along the myogenic pathway and participates in muscle repair in the $\mathrm{mdx}$ dystrophic mouse," Experimental Cell Research, vol. 277, no. 1, pp. 74-85, 2002.

[89] C. Dell'Agnola, Z. Wang, R. Storb et al., "Hematopoietic stem cell transplantation does not restore dystrophin expression in Duchenne muscular dystrophy dogs," Blood, vol. 104, no. 13, pp. 4311-4318, 2004.

[90] E. Gussoni, R. R. Bennett, K. R. Muskiewicz et al., "Long-term persistence of donor nuclei in a Duchenne muscular dystrophy patient receiving bone marrow transplantation," Journal of Clinical Investigation, vol. 110, no. 6, pp. 807-814, 2002.

[91] P. B. Kang, H. G. W. Lidov, A. J. White et al., "Inefficient dystrophin expression after cord blood transplantation in duchenne muscular dystrophy," Muscle \& Nerve, vol. 41, no. 6, pp. 746-750, 2010.

[92] F. D. Camargo, R. Green, Y. Capetenaki, K. A. Jackson, and M. A. Goodell, "Single hematopoietic stem cells generate skeletal muscle through myeloid intermediates," Nature Medicine, vol. 9, no. 12, pp. 1520-1527, 2003.

[93] G. Wernig, V. Janzen, R. Schäfer et al., "The vast majority of bone-marrow-derived cells integrated into $\mathrm{mdx}$ muscle fibers are silent despite long-term engraftment," Proceedings of the National Academy of Sciences of the United States of America, vol. 102, no. 33, pp. 11852-11857, 2005.

[94] L. De Angelis, L. Berghella, M. Coletta et al., "Skeletal myogenic progenitors originating from embryonic dorsal aorta coexpress endothelial and myogenic markers and contribute to postnatal muscle growth and regeneration," Journal of Cell Biology, vol. 147, no. 4, pp. 869-877, 1999.

[95] R. Tonlorenzi, A. Dellavalle, E. Schnapp, G. Cossu, and M. Sampaolesi, "Isolation and characterization of mesoangioblasts from mouse, dog, and human tissues," Current protocols in stem cell biology, vol. 2, Article ID 2B1, 2007.

[96] K. E. Davies and M. D. Grounds, "Treating muscular dystrophy with stem cells?” Cell, vol. 127, no. 7, pp. 1304-1306, 2006.

[97] M. D. Grounds and K. E. Davies, "The allure of stem cell therapy for muscular dystrophy," Neuromuscular Disorders, vol. 17, no. 3, pp. 206-208, 2007.

[98] A. H. Bretag, "Stem cell treatment of dystrophic dogs," Nature, vol. 450, no. 7173, pp. E23-E25, 2007.
[99] F. S. Tedesco, A. Dellavalle, J. Diaz-Manera, G. Messina, and G. Cossu, "Repairing skeletal muscle: regenerative potential of skeletal muscle stem cells," Journal of Clinical Investigation, vol. 120, no. 1, pp. 11-19, 2010.

[100] K. K. Hirschi and P. A. D'Amore, "Pericytes in the microvasculature," Cardiovascular Research, vol. 32, no. 4, pp. 687-698, 1996.

[101] M. J. Doherty, B. A. Ashton, S. Walsh, J. N. Beresford, M. E. Grant, and A. E. Canfield, "Vascular pericytes express osteogenic potential in vitro and in vivo," Journal of Bone and Mineral Research, vol. 13, no. 5, pp. 828-838, 1998.

[102] C. Farrington-Rock, N. J. Crofts, M. J. Doherty, B. A. Ashton, C. Griffin-Jones, and A. E. Canfield, "Chondrogenic and adipogenic potential of microvascular pericytes," Circulation, vol. 110, no. 15, pp. 2226-2232, 2004.

[103] I. Kirillova, E. Gussoni, D. J. Goldhamer, and Z. YablonkaReuveni, "Myogenic reprogramming of retina-derived cells following their spontaneous fusion with myotubes," Developmental Biology, vol. 311, no. 2, pp. 449-463, 2007.

[104] A. Dellavalle, G. Maroli, D. Covarello et al., "Pericytes resident in postnatal skeletal muscle differentiate into muscle fibres and generate satellite cells," Nature Communications, vol. 2, no. 1, p. 499, 2011.

[105] A. B. Borisov, "Regeneration of skeletal and cardiac muscle in mammals: do nonprimate models resemble human pathology?" Wound Repair and Regeneration, vol. 7, no. 1, pp. 26-35, 1999.

[106] H. Puchtler, F. Sweat, M. S. Terry, and H. M. Conner, "Investigation of staining, polarization and fluorescence-microscopic properties of myoendothelial cells," Journal of Microscopy, vol. 89, no. 1, pp. 95-104, 1969.

[107] A. H. Yin, S. Miraglia, E. D. Zanjani et al., "AC133, a novel marker for human hematopoietic stem and progenitor cells," Blood, vol. 90, no. 12, pp. 5002-5012, 1997.

[108] Y. Torrente, M. Belicchi, M. Sampaolesi et al., "Human circulating AC133+ stem cells restore dystrophin expression and ameliorate function in dystrophic skeletal muscle," Journal of Clinical Investigation, vol. 114, no. 2, pp. 182-195, 2004.

[109] Y. Torrente, M. Belicchi, C. Marchesi et al., "Autologous transplantation of muscle-derived CD133+ stem cells in Duchenne muscle patients," Cell Transplantation, vol. 16, no. 6, pp. 563577, 2007.

[110] Z. Qu, L. Balkir, J. C. T. Van Deutekom, P. D. Robbins, R. Pruchnic, and J. Huard, "Development of approaches to improve cell survival in myoblast transfer therapy," Journal of Cell Biology, vol. 142, no. 5, pp. 1257-1267, 1998.

[111] G. M. Mueller, T. O’Day, J. F. Watchko, and M. Ontell, “Effect of injecting primary myoblasts versus putative muscle-derived stem cells on mass and force generation in mdx mice," Human Gene Therapy, vol. 13, no. 9, pp. 1081-1090, 2002.

[112] A. Asakura, P. Seale, A. Girgis-Gabardo, and M. A. Rudnicki, "Myogenic specification of side population cells in skeletal muscle," Journal of Cell Biology, vol. 159, no. 1, pp. 123-134, 2002.

[113] R. Sarig, Z. Baruchi, O. Fuchs, U. Nudel, and D. Yaffe, "Regeneration and transdifferentiation potential of muscle-derived stem cells propagated as myospheres," Stem Cells, vol. 24, no. 7, pp. 1769-1778, 2006.

[114] D. N. Landon, "Skeletal muscle: normal morphology, development and innervation," in Skeletal Muscle Pathology, pp. 1-87, Churchil Livingstone, Edinburgh, UK, 1982.

[115] D. Skuk and J. P. Tremblay, "Intramuscular cell transplantation as a potential treatment of myopathies: clinical and preclinical relevant data," Expert Opinion on Biological Therapy, vol. 11, no. 3, pp. 359-374, 2011. 
[116] A. M. Neumeyer, D. M. DiGregorio, and R. H. Brown Jr., "Arterial delivery of myoblasts to skeletal muscle," Neurology, vol. 42, no. 12, pp. 2258-2262, 1992.

[117] T. A. Partridge, "Invited review: myoblast transfer: a possible therapy for inherited myopathies?" Muscle \& Nerve, vol. 14, no. 3, pp. 197-212, 1991.

[118] E. Bachrach, A. L. Perez, Y. Choi et al., "Muscle engraftment of myogenic progenitor cells following intraarterial transplantation," Muscle \& Nerve, vol. 34, no. 1, pp. 44-52, 2006.

[119] Y. Torrente, J.-P. Tremblay, F. Pisati et al., "Intraarterial injection of muscle-derived CD34+Sca-1+ stem cells restores dystrophin in mdx mice," Journal of Cell Biology, vol. 152, no. 2, pp. 335-348, 2001.

[120] D. Skuk, M. Goulet, and J. P. Tremblay, "Use of repeating dispensers to increase the efficiency of the intramuscular myogenic cell injection procedure," Cell Transplantation, vol. 15, no. 7, pp. 659-663, 2006.

[121] D. Skuk, M. Goulet, B. Roy, and J. P. Tremblay, "Myoblast transplantation in whole muscle of nonhuman primates," Journal of Neuropathology and Experimental Neurology, vol. 59, no. 3, pp. 197-206, 2000.

[122] D. Skuk, M. Goulet, B. Roy, and J. P. Tremblay, "Efficacy of myoblast transplantation in nonhuman primates following simple intramuscular cell injections: toward defining strategies applicable to humans," Experimental Neurology, vol. 175, no. 1, pp. 112-126, 2002.

[123] D. Skuk, M. Goulet, and J. P. Tremblay, "Use of repeating dispensers to increase the efficiency of the intramuscular myogenic cell injection procedure," Cell Transplantation, vol. 15, no. 7, pp. 659-663, 2006.

[124] D. Skuk, "Myoblast transplantion for inherited myopathies: a clinical approach," Expert Opinion on Biological Therapy, vol. 4, no. 12, pp. 1871-1885, 2004.

[125] D. Skuk, M. Goulet, and J. P. Tremblay, "Transplanted myoblasts can migrate several millimeters to fuse with damaged myofibers in nonhuman primate skeletal muscle," Journal of Neuropathology and Experimental Neurology, vol. 70, no. 9, pp. 770-778, 2011.

[126] D. Skuk, M. Goulet, and J. P. Tremblay, "Electroporation as method to induce myofiber regeneration and increase the engraftment of myogenic cells in skeletal muscles of primates," Jornal of Neuropathololgy and Experimenbtal Neurology, vol. 72, no. 8, pp. 723-734, 2013.

[127] P. D. Moens, M. C. Van-Schoor, and G. Maréchal, "Lack of myoblasts migration between transplanted and host muscles of mdx and normal mice," Journal of Muscle Research and Cell Motility, vol. 17, no. 1, pp. 37-43, 1996.

[128] T. A. Robertson, M. A. L. Maley, M. D. Grounds, and J. M. Papadimitriou, "The role of macrophages in skeletal muscle regeneration with particular reference to chemotaxis," Experimental Cell Research, vol. 207, no. 2, pp. 321-331, 1993.

[129] R. Bischoff, "Chemotaxis of skeletal muscle satellite cells," Developmental Dynamics, vol. 208, no. 4, pp. 505-515, 1997.

[130] Y. Tokura, Y. Nakayama, S. Fukada et al., "Muscle injuryinduced thymosin $\beta 4$ acts as a chemoattractant for myoblasts," Journal of Biochemistry, vol. 149, no. 1, pp. 43-48, 2011.

[131] A. L. Siegel, K. Atchison, K. E. Fisher, G. E. Davis, and D. D. W. Cornelison, "3D timelapse analysis of muscle satellite cell motility," Stem Cells, vol. 27, no. 10, pp. 2527-2538, 2009.

[132] S. P. Quenneville, P. Chapdelaine, D. Skuk et al., "Autologous transplantation of muscle precursor cells modified with a lentivirus for muscular dystrophy: human cells and primate models," Molecular Therapy, vol. 15, no. 2, pp. 431-438, 2007.

[133] E. El Fahime, P. Mills, J. F. Lafreniere, Y. Torrente, and J. P. Tremblay, "The urokinase plasminogen activator: an interesting way to improve myoblast migration following their transplantation," Experimental Cell Research, vol. 280, no. 2, pp. 169-178, 2002.

[134] J. F. Lafreniere, P. Mills, M. Bouchentouf, and J. P. Tremblay, "Interleukin-4 improves the migration of human myogenic precursor cells in vitro and in vivo," Experimental Cell Research, vol. 312, no. 7, pp. 1127-1141, 2006.

[135] P. Mills, J. C. Dominique, J. F. Lafrenière, M. Bouchentouf, and J. P. Tremblay, "A synthetic mechano growth factor E peptide enhances myogenic precursor cell transplantation success," American Journal of Transplantation, vol. 7, no. 10, pp. 22472259, 2007.

[136] P. Mills, J. Lafrenière, B. F. Benabdallah, E. M. El Fahime, and J. Tremblay, "A new pro-migratory activity on human myogenic precursor cells for a synthetic peptide within the E domain of the mechano growth factor," Experimental Cell Research, vol. 313, no. 3, pp. 527-537, 2007.

[137] J. F. Lafreniere, M. C. Caron, D. Skuk, M. Goulet, A. R. Cheikh, and J. P. Tremblay, "Growth factor coinjection improves the migration potential of monkey myogenic precursors without affecting cell transplantation success," Cell Transplantation, vol. 18, no. 7, pp. 719-730, 2009.

[138] C. Pichavant, C. Gargioli, and J. P. Tremblay, "Intramuscular transplantation of muscle precursor cells over-expressing MMP-9 improves transplantation success," PLOS Currents, vol. 3, Article ID RRN1275, 2011.

[139] J. T. Vilquin, I. Asselin, B. Guerette, I. Kinoshita, R. Roy, and J. P. Tremblay, "Successful myoblast allotransplantation in mdx mice using rapamycin," Transplantation, vol. 59, no. 3, pp. 422426, 1995.

[140] C. Lazerges, P. Daussin, B. Coulet et al., "Transplantation of primary satellite cells improves properties of reinnervated skeletal muscles," Muscle \& Nerve, vol. 29, no. 2, pp. 218-226, 2004.

[141] M. Bouchentouf, B. F. Benabdallah, P. Bigey, T. M. Yau, D. Scherman, and J. P. Tremblay, "Vascular endothelial growth factor reduced hypoxia-induced death of human myoblasts and improved their engraftment in mouse muscles," Gene Therapy, vol. 15, no. 6, pp. 404-414, 2008.

[142] J. G. Gross, G. Bou-Gharios, and J. E. Morgan, "Potentiation of myoblast transplantation by host muscle irradiation is dependent on the rate of radiation delivery," Cell and Tissue Research, vol. 298, no. 2, pp. 371-375, 1999.

[143] D. Skuk, B. Roy, M. Goulet, and J. P. Tremblay, "Successful myoblast transplantation in primates depends on appropriate cell delivery and induction of regeneration in the host muscle," Experimental Neurology, vol. 155, no. 1, pp. 22-30, 1999.

[144] B. M. Carlson, "Muscle regeneration in animal models," in Skeletal Muscle Repair and Regeneration, pp. 163-179, Springer, Dordrecht, The Netherlands, 2008.

[145] I. Kinoshita, J. T. Vilquin, I. Asselin, J. Chamberlain, and J. P. Tremblay, "Transplantation of myoblasts from a transgenic mouse overexpressing dystrophin produced only a relatively small increase of dystrophin- positive membrane," Muscle \& Nerve, vol. 21, no. 1, pp. 91-103, 1998.

[146] P. L. Richard, C. Gosselin, T. Laliberté et al., "A first semimanual device for clinical intramuscular repetitive cell injections," Cell Transplantation, vol. 19, no. 1, pp. 67-78, 2010. 
[147] J. R. Beauchamp, J. E. Morgan, C. N. Pagel, and T. A. Partridge, "Quantitative studies of efficacy of myoblast transplantation," Muscle \& Nerve, supplement 4, p. S261, 1994.

[148] J. Huard, G. Acsadi, A. Jani, B. Massie, and G. Karpati, "Gene transfer into skeletal muscles by isogenic myoblasts," Human Gene Therapy, vol. 5, no. 8, pp. 949-958, 1994.

[149] B. Guérette, D. Skuk, F. Célestin et al., "Prevention by anti-LFA1 of acute myoblast death following transplantation," Journal of Immunology, vol. 159, no. 5, pp. 2522-2531, 1997.

[150] J. R. Beauchamp, J. E. Morgan, C. N. Pagel, and T. A. Partridge, "Dynamics of myoblast transplantation reveal a discrete minority of precursors with stem cell-like properties as the myogenic source," Journal of Cell Biology, vol. 144, no. 6, pp. 1113-1121, 1999.

[151] D. Skuk, N. J. Caron, M. Goulet, B. Roy, and J. P. Tremblay, "Resetting the problem of cell death following muscle-derived cell transplantation: detection, dynamics and mechanisms," Journal of Neuropathology and Experimental Neurology, vol. 62, no. 9, pp. 951-967, 2003.

[152] I. Riederer, E. Negroni, A. Bigot et al., "Heat shock treatment increases engraftment of transplanted human myoblasts into immunodeficient mice," Transplantation Proceedings, vol. 40, no. 2, pp. 624-630, 2008.

[153] J. C. Cousins, K. J. Woodward, J. G. Gross, T. A. Partridge, and J. E. Morgan, "Regeneration of skeletal muscle from transplanted immortalised myoblasts is oligoclonal," Journal of Cell Science, vol. 117, no. 15, pp. 3259-3269, 2004.

[154] S. I. Hodgetts, M. W. Beilharz, A. A. Scalzo, and M. D. Grounds, "Why do cultured transplanted myoblasts die in vivo? DNA quantification shows enhanced survival of donor male myoblasts in host mice depleted of CD4+ and CD8+ cells or NK1.1+ cells," Cell Transplantation, vol. 9, no. 4, pp. 489-502, 2000.

[155] S. I. Hodgetts and M. D. Grounds, "Complement and myoblast transfer therapy: donor myoblast survival is enhanced following depletion of host complement $\mathrm{C} 3$ using cobra venom factor, but not in the absence of C5," Immunology and Cell Biology, vol. 79, no. 3, pp. 231-239, 2001.

[156] L. M. Sammels, E. Bosio, C. T. Fragall, M. D. Grounds, N. Van Rooijen, and M. W. Beilharz, "Innate inflammatory cells are not responsible for early death of donor myoblasts after myoblast transfer therapy," Transplantation, vol. 77, no. 12, pp. 1790-1797, 2004.

[157] B. Guérette, I. Asselin, D. Skuk, M. Entman, and J. P. Tremblay, "Control of inflammatory damage by anti-LFA-1: increase success of myoblast transplantation," Cell Transplantation, vol. 6, no. 2, pp. 101-107, 1997.

[158] P. F. Lesault, M. Theret, M. Magnan et al., "Macrophages improve survival, proliferation and migration of engrafted myogenic precursor cells into MDX skeletal muscle," PLoS One, vol. 7, no. 10, Article ID e46698, 2012.

[159] D. Skuk, N. Caron, M. Goulet, B. Roy, F. Espinosa, and J. P. Tremblay, "Dynamics of the early immune cellular reactions after myogenic cell transplantation," Cell Transplantation, vol. 11, no. 7, pp. 671-681, 2002.

[160] M. Bouchentouf, B. F. Benabdallah, J. Rousseau, L. M. Schwartz, and J. P. Tremblay, "Induction of anoikis following myoblast transplantation into SCID mouse muscles requires the Bitl and FADD pathways," American Journal of Transplantation, vol. 7, no. 6, pp. 1491-1505, 2007.

[161] M. Bouchentouf, B. F. Benabdallah, and J. P. Tremblay, "Myoblast survival enhancement and transplantation success improvement by heat-shock treatment in MDX mice," Transplantation, vol. 77, no. 9, pp. 1349-1356, 2004.

[162] R. Fakhfakh, Y. Lamarre, D. Skuk, and J. P. Tremblay, "Losartan enhances the success of myoblast transplantation," Cell Transplantation, vol. 21, no. 1, pp. 139-152, 2012.

[163] C. Gerard, C. Dufour, S. Goudenege, D. Skuk, and J. P. Tremblay, "AG490 improves the survival of human myoblasts in vitro and in vivo," Cell Transplantation, vol. 21, no. 12, pp. 2665-2676, 2012.

[164] C. Gerard, M. A. Forest, G. Beauregard, D. Skuk, and J. P. Tremblay, "Fibrin gel improves the survival of transplanted myoblasts," Cell Transplantation, vol. 21, no. 1, pp. 127-137, 2012.

[165] D. Skuk, M. Paradis, M. Goulet, and J. P. Tremblay, "Ischemic central necrosis in pockets of transplanted myoblasts in nonhuman primates: implications for cell-transplantation strategies," Transplantation, vol. 84, no. 10, pp. 1307-1315, 2007.

[166] B. A. J. Ponder, M. M. Wilkinson, M. Wood, and J. H. Westwood, "Immunohistochemical demonstration of $\mathrm{H} 2$ antigens in mouse tissue sections," Journal of Histochemistry and Cytochemistry, vol. 31, no. 7, pp. 911-919, 1983.

[167] S. T. Appleyard, M. J. Dunn, V. Dubowitz, and M. L. Rose, "Increased expression of HLA ABC class I antigens by muscle fibres in Duchenne muscular dystrophy, inflammatory myopathy, and other neuromuscular disorders," The Lancet, vol. 1, no. 8425, pp. 361-363, 1985.

[168] G. Karpati, Y. Pouliot, and S. Carpenter, "Expression of immunoreactive major histocompatibility complex products in human skeletal muscles," Annals of Neurology, vol. 23, no. 1, pp. 64-72, 1988.

[169] A. M. Emslie-Smith, K. Arahata, and A. G. Engel, "Major histocompatibility complex class I antigen expression, immunolocalization of interferon subtypes, and T cell-mediated cytotoxicity in myopathies," Human Pathology, vol. 20, no. 3, pp. 224-231, 1989.

[170] R. Mantegazza, S. M. Hughes, D. Mitchell, M. Travis, H. M. Blau, and L. Steinman, "Modulation of MHC class II antigen expression in human myoblasts after treatment with IFN- $\gamma$," Neurology, vol. 41, no. 7, pp. 1128-1132, 1991.

[171] C. Cifuentes-Diaz, C. Delaporte, B. Dautreaux, D. Charron, and M. Fardeau, "Class II MHC antigens in normal human skeletal muscle," Muscle \& Nerve, vol. 15, no. 3, pp. 295-302, 1992.

[172] D. Michaelis, N. Goebels, and R. Hohlfeld, "Constitutive and cytokine-induced expression of human leukocyte antigens and cell adhesion molecules by human myotubes," American Journal of Pathology, vol. 143, no. 4, pp. 1142-1149, 1993.

[173] P. H. Jones, "Implantation of cultured regenerate muscle cells into adult rat muscle," Experimental Neurology, vol. 66, no. 3, pp. 602-610, 1979.

[174] B. Guerette, I. Asselin, J. T. Vilquin, R. Roy, and J. P. Tremblay, "Lymphocyte infiltration following allo- and xenomyoblast transplantation in mdx mice," Muscle \& Nerve, vol. 18, no. 1, pp. 39-51, 1995.

[175] A. Irintchev, M. Zweyer, and A. Wernig, "Cellular and molecular reactions in mouse muscles after myoblast implantation," Journal of Neurocytology, vol. 24, no. 4, pp. 319-331, 1995.

[176] A. Wernig and A. Irintchev, "'Bystander' damage of host muscle caused by implantation of MHC-compatible myogenic cells," Journal of the Neurological Sciences, vol. 130, no. 2, pp. 190-196, 1995.

[177] B. Guerette, R. Roy, M. Tremblay et al., "Increased granzyme B mRNA after alloincompatible myoblast transplantation," Transplantation, vol. 60, no. 9, pp. 1011-1016, 1995. 
[178] B. Guerette, G. Tremblay, J. T. Vilquin et al., "Increased interferon-gamma mRNA expression following alloincompatible myoblast transplantation is inhibited by FK506," Muscle \& Nerve, vol. 19, no. 7, pp. 829-835, 1996.

[179] A. Boulanger, I. Asselin, R. Roy, and J. P. Tremblay, "Role of nonmajor histocompatibility complex antigens in the rejection of transplanted myoblasts," Transplantation, vol. 63, no. 6, pp. 893899, 1997.

[180] D. Skuk, "Acute rejection of myofibers in nonhuman primates: key histopathologic features," Journal of Neuropathology and Experimental Neurology, vol. 71, no. 5, pp. 398-412, 2012.

[181] D. Skuk and J. P. Tremblay, "Necrosis, sarcolemmal damage and apoptotic events in myofibers rejected by CD8+ lymphocytes: observations in nonhuman primates," Neuromuscular Disorders, vol. 22, no. 11, pp. 997-1005, 2012.

[182] J. T. Vilquin, I. Kinoshita, R. Roy, and J. P. Tremblay, "Cyclophosphamide immunosuppression does not permit successful myoblast allotransplantation in mouse," Neuromuscular Disorders, vol. 5, no. 6, pp. 511-517, 1995.

[183] G. K. Pavlath, T. A. Rando, and H. M. Blau, "Transient immunosuppressive treatment leads to long-term retention of allogeneic myoblasts in hybrid myofibers," Journal of Cell Biology, vol. 127, no. 6, pp. 1923-1932, 1994.

[184] I. Asselin, M. Tremblay, J.-T. Vilquin, B. Guerette, R. Roy, and J. P. Tremblay, "Quantification of normal dystrophin mRNA following myoblast transplantation in mdx mice," Muscle \& Nerve, vol. 18, no. 9, pp. 980-986, 1995.

[185] O. Hardiman, R. M. Sklar, and R. H. Brown Jr., "Direct effects of cyclosporin A and cyclophosphamide on differentiation of normal human myoblasts in culture," Neurology, vol. 43, no. 7, pp. 1432-1434, 1993.

[186] F. Hong, J. Lee, J. Song et al., "Cyclosporin A blocks muscle differentiation by inducing oxidative stress and inhibiting the peptidyl-prolyl-cis-trans isomerase activity of cyclophilin A: cyclophilin A protects myoblasts from cyclosporin A-induced cytotoxicity," The FASEB Journal, vol. 16, no. 12, pp. 1633-1635, 2002.

[187] G. Camirand, N. J. Caron, I. Asselin, and J. P. Tremblay, "Combined immunosuppression of mycophenolate mofetil and FK506 for myoblast transplantation in mdx mice," Transplantation, vol. 72, no. 1, pp. 38-44, 2001.

[188] J.-T. Vilquin, I. Asselin, B. Guerette et al., "Myoblast allotransplantation in mice: degree of success varies depending on the efficacy of various immunosuppressive treatments," Transplantation Proceedings, vol. 26, no. 6, pp. 3372-3373, 1994.

[189] B. Guérette, M. Gingras, K. Wood, R. Roy, and J. P. Tremblay, "Immunosuppression with monoclonal antibodies and CTLA4-Ig after myoblast transplantation in mice," Transplantation, vol. 62, no. 7, pp. 962-967, 1996.

[190] I. Kinoshita, J. T. Vilquin, C. Gravel, R. Roy, and J. P. Tremblay, "Myoblast allotransplantation in primates," Muscle \& Nerve, vol. 18, no. 10, pp. 1217-1218, 1995.

[191] I. Kinoshita, R. Roy, F. J. Dugré et al., "Myoblast transplantation in monkeys: control of immune response by FK506," Journal of Neuropathology and Experimental Neurology, vol. 55, no. 6, pp. 687-697, 1996.

[192] C. Semsarian, M. Wu, Y. Ju et al., "Skeletal muscle hypertrophy is mediated by a $\mathrm{Ca}^{2+}$-dependent calcineurin signalling pathway," Nature, vol. 400, no. 6744, pp. 576-581, 1999.

[193] D. Chandrasekharan, F. Issa, and K. J. Wood, "Achieving operational tolerance in transplantation: how can lessons from the clinic inform research directions?” Transplant International, vol. 26, no. 6, pp. 576-589, 2013.

[194] G. Camirand, J. Rousseau, M. Ducharme, D. M. Rothstein, and J. P. Tremblay, "Novel Duchenne muscular dystrophy treatment through myoblast transplantation tolerance with anti-CD45RB, anti-CD154 and mixed chimerism," American Journal of Transplantation, vol. 4, no. 8, pp. 1255-1265, 2004.

[195] L. Stephan, C. Pichavant, M. Bouchentouf et al., "Induction of tolerance across fully mismatched barriers by a nonmyeloablative treatment excluding antibodies or irradiation use," Cell Transplantation, vol. 15, no. 8-9, pp. 835-846, 2006.

[196] G. Camirand, N. J. Caron, N. A. Turgeon, A. A. Rossini, and J. P. Tremblay, "Treatment with anti-CD154 antibody and donor specific transfusion prevents acute rejection of myoblast transplantation," Transplantation, vol. 73, no. 3, pp. 453-461, 2002.

[197] G. Camirand, L. Stéphan, J. Rousseau et al., "Central tolerance to myogenic cell transplants does not include muscle neoantigens," Transplantation, vol. 85, no. 12, pp. 1791-1801, 2008.

[198] S. P. Quenneville and J. P. Tremblay, "Ex vivo modification of cells to induce a muscle-based expression," Current Gene Therapy, vol. 6, no. 6, pp. 625-632, 2006.

[199] Y. Ohtsuka, K. Udaka, Y. Yamashiro, H. Yagita, and K. Okumura, "Dystrophin acts as a transplantation rejection antigen in dystrophin- deficient mice: implication for gene therapy," Journal of Immunology, vol. 160, no. 9, pp. 4635-4640, 1998.

[200] S. S. Floyd Jr., P. R. Clemens, M. R. Ontell et al., " $E x$ vivo gene transfer using adenovirus-mediated full-length dystrophin delivery to dystrophic muscles," Gene Therapy, vol. 5, no. 1, pp. 19-30, 1998.

[201] P.-A. Moisset, Y. Gagnon, G. Karpati, and J. P. Tremblay, "Expression of human dystrophin following the transplantation of genetically modified mdx myoblasts," Gene Therapy, vol. 5, no. 10, pp. 1340-1346, 1998.

[202] P. Moisset, D. Skuk, I. Asselin et al., "Successful transplantation of genetically corrected DMD myoblasts following ex vivo transduction with the dystrophin minigene," Biochemical and Biophysical Research Communications, vol. 247, no. 1, pp. 94-99, 1998.

[203] D. Escors and K. Breckpot, "Lentiviral vectors in gene therapy: their current status and future potential," Archivum Immunologiae et Therapiae Experimentalis, vol. 58, no. 2, pp. 107-119, 2010.

[204] C. Pichavant and J. P. Tremblay, "Generation of lentiviral vectors for use in skeletal muscle research," Methods in Molecular Biology, vol. 798, pp. 285-295, 2012.

[205] C. E. Thomas, A. Ehrhardt, and M. A. Kay, "Progress and problems with the use of viral vectors for gene therapy," Nature Reviews Genetics, vol. 4, no. 5, pp. 346-358, 2003.

[206] M. Bokhoven, S. L. Stephen, S. Knight et al., "Insertional gene activation by lentiviral and gammaretroviral vectors," Journal of Virology, vol. 83, no. 1, pp. 283-294, 2009.

[207] Z. Ivics and Z. Izsvák, “Transposons for gene therapy!," Current Gene Therapy, vol. 6, no. 5, pp. 593-607, 2006.

[208] H. F. Willard, "Human artificial chromosomes coming into focus," Nature Biotechnology, vol. 16, no. 5, pp. 415-417, 1998.

[209] H. Hoshiya, Y. Kazuki, S. Abe et al., "A highly stable and nonintegrated human artificial chromosome (HAC) containing the $2.4 \mathrm{Mb}$ entire human dystrophin gene," Molecular Therapy, vol. 17, no. 2, pp. 309-317, 2009.

[210] Y. Kazuki, M. Hiratsuka, M. Takiguchi et al., "Complete genetic correction of iPS cells from duchenne muscular dystrophy," Molecular Therapy, vol. 18, no. 2, pp. 386-393, 2010. 
[211] F. S. Tedesco, H. Hoshiya, G. D’Antona et al., "Stem cellmediated transfer of a human artificial chromosome ameliorates muscular dystrophy," Science Translational Medicine, vol. 3, no. 96, Article ID 96ra78, 2011.

[212] C. Webster and H. M. Blau, "Accelerated age-related decline in replicative life-span of Duchenne muscular dystrophy myoblasts: implications for cell and gene therapy," Somatic Cell and Molecular Genetics, vol. 16, no. 6, pp. 557-565, 1990.

[213] L. V. Simon, J. R. Beauchamp, M. O’Hare, and I. Olsen, "Establishment of long-term myogenic cultures from patients with Duchenne muscular dystrophy by retroviral transduction of a temperature-sensitive SV40 large T antigen," Experimental Cell Research, vol. 224, no. 2, pp. 264-271, 1996.

[214] S. Seigneurin-Venin, V. Bernard, P. Moisset et al., "Transplantation of normal and DMD myoblasts expressing the telomerase gene in SCID mice," Biochemical and Biophysical Research Communications, vol. 272, no. 2, pp. 362-369, 2000.

[215] S. Seigneurin-Venin, V. Bernard, and J. P. Tremblay, "Telomerase allows the immortalization of $\mathrm{T}$ antigen-positive $\mathrm{DMD}$ myoblasts: a new source of cells for gene transfer application," Gene Therapy, vol. 7, no. 7, pp. 619-623, 2000.

[216] C. Huard, P. Moisset, A. Dicaire et al., "Transplantation of dermal fibroblasts expressing MyoD1 in mouse muscles," Biochemical and Biophysical Research Communications, vol. 248, no. 3, pp. 648-654, 1998.

[217] K. Goldring, G. E. Jones, C. A. Sewry, and D. J. Watt, "The muscle-specific marker desmin is expressed in a proportion of human dermal fibroblasts after their exposure to galectin-1," Neuromuscular Disorders, vol. 12, no. 2, pp. 183-186, 2002.

[218] K. Goldring, G. E. Jones, R. Thiagarajah, and D. J. Watt, “The effect of galectin-1 on the differentiation of fibroblasts and myoblasts in vitro," Journal of Cell Science, vol. 115, no. 2, pp. 355-366, 2002.

[219] M. Wernig, A. Meissner, R. Foreman et al., "In vitro reprogramming of fibroblasts into a pluripotent ES-cell-like state," Nature, vol. 448, no. 7151, pp. 318-324, 2007.

[220] K. Takahashi, K. Tanabe, M. Ohnuki et al., "Induction of pluripotent stem cells from adult human fibroblasts by defined factors," Cell, vol. 131, no. 5, pp. 861-872, 2007.

[221] Y. Mizuno, H. Chang, K. Umeda et al., "Generation of skeletal muscle stem/progenitor cells from murine induced pluripotent stem cells," FASEB Journal, vol. 24, no. 7, pp. 2245-2253, 2010.

[222] R. Darabi, W. Pan, D. Bosnakovski, J. Baik, M. Kyba, and R. C. R. Perlingeiro, "Functional myogenic engraftment from mouse iPS cells," Stem Cell Reviews and Reports, vol. 7, no. 4, pp. 948957, 2011.

[223] R. Darabi, R. W. Arpke, S. Irion et al., "Human ES- and iPS-derived myogenic progenitors restore DYSTROPHIN and improve contractility upon transplantation in dystrophic mice," Cell Stem Cell, vol. 10, no. 5, pp. 610-619, 2012.

[224] A. Filareto, S. Parker, R. Darabi et al., "An ex vivo gene therapy approach to treat muscular dystrophy using inducible pluripotent stem cells," Nature Communications, vol. 4, Article ID 1549, 2013.

[225] S. Goudenege, C. Lebel, N. B. Huot et al., "Myoblasts derived from normal hESCs and dystrophic hiPSCs efficiently fuse with existing muscle fibers following transplantation," Molecular Therapy, vol. 20, no. 11, pp. 2153-2167, 2012. 


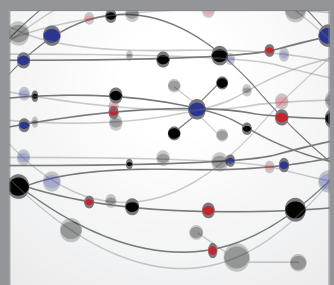

The Scientific World Journal
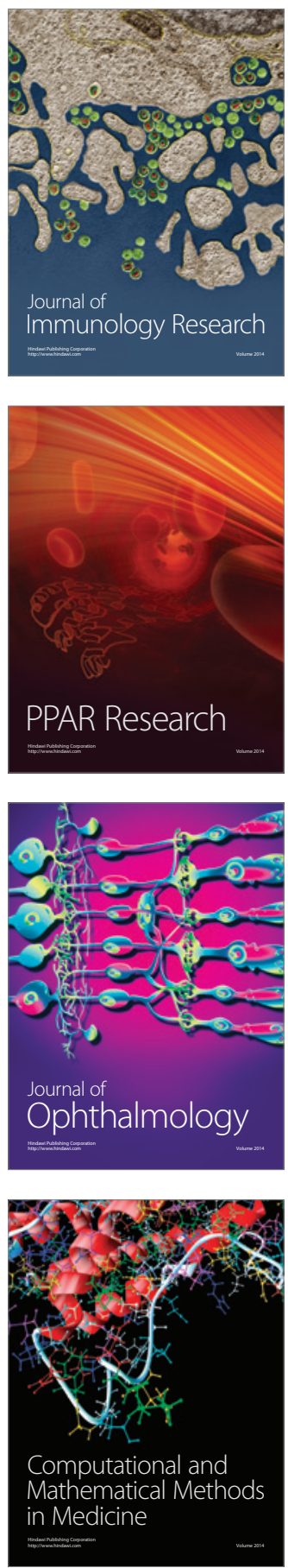

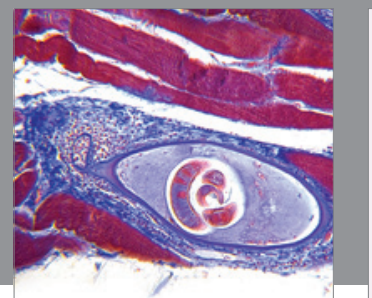

Gastroenterology

Research and Practice
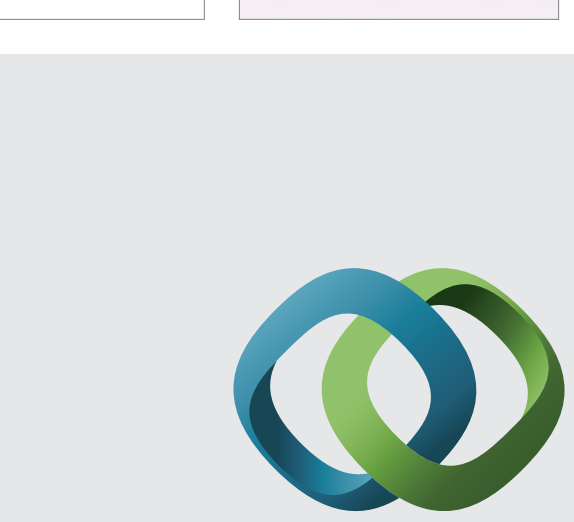

\section{Hindawi}

Submit your manuscripts at

http://www.hindawi.com
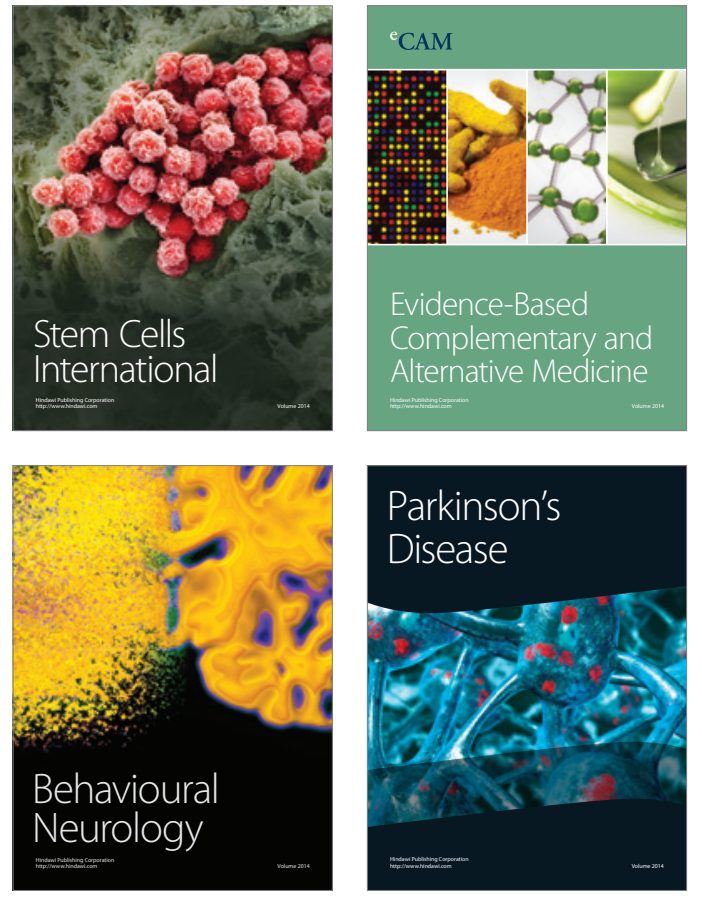
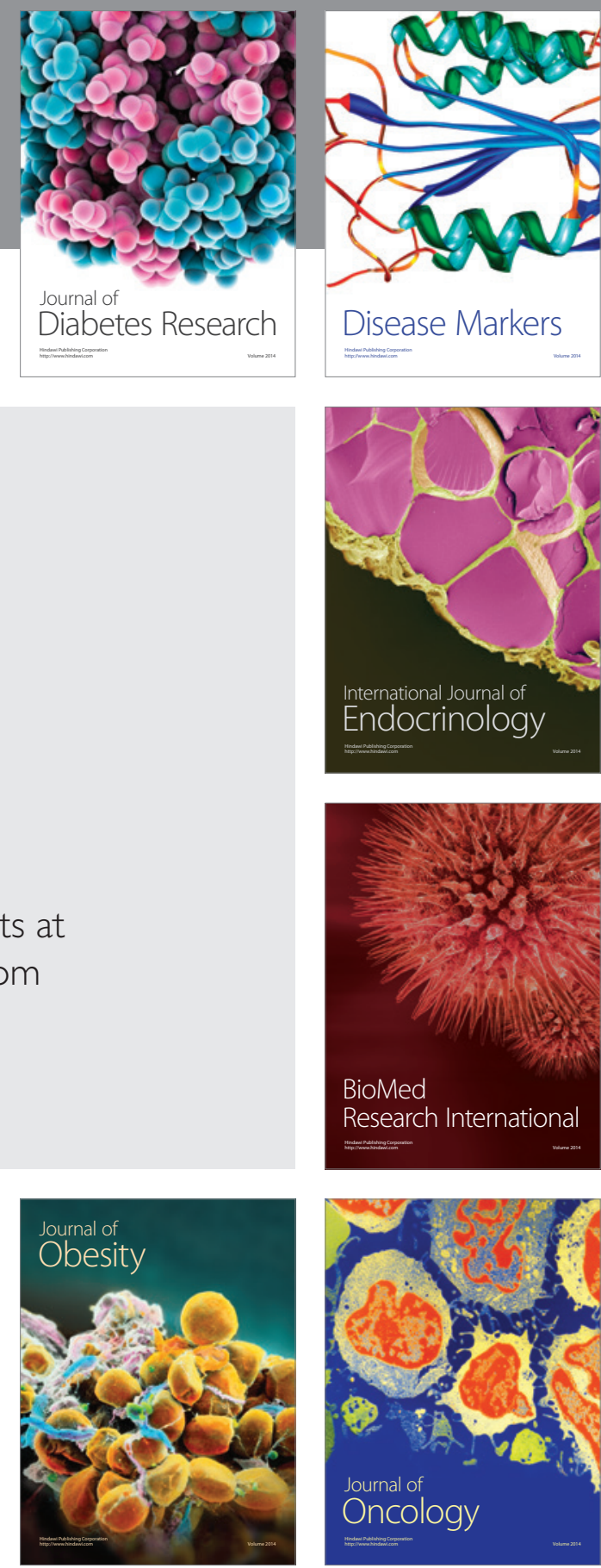

Disease Markers
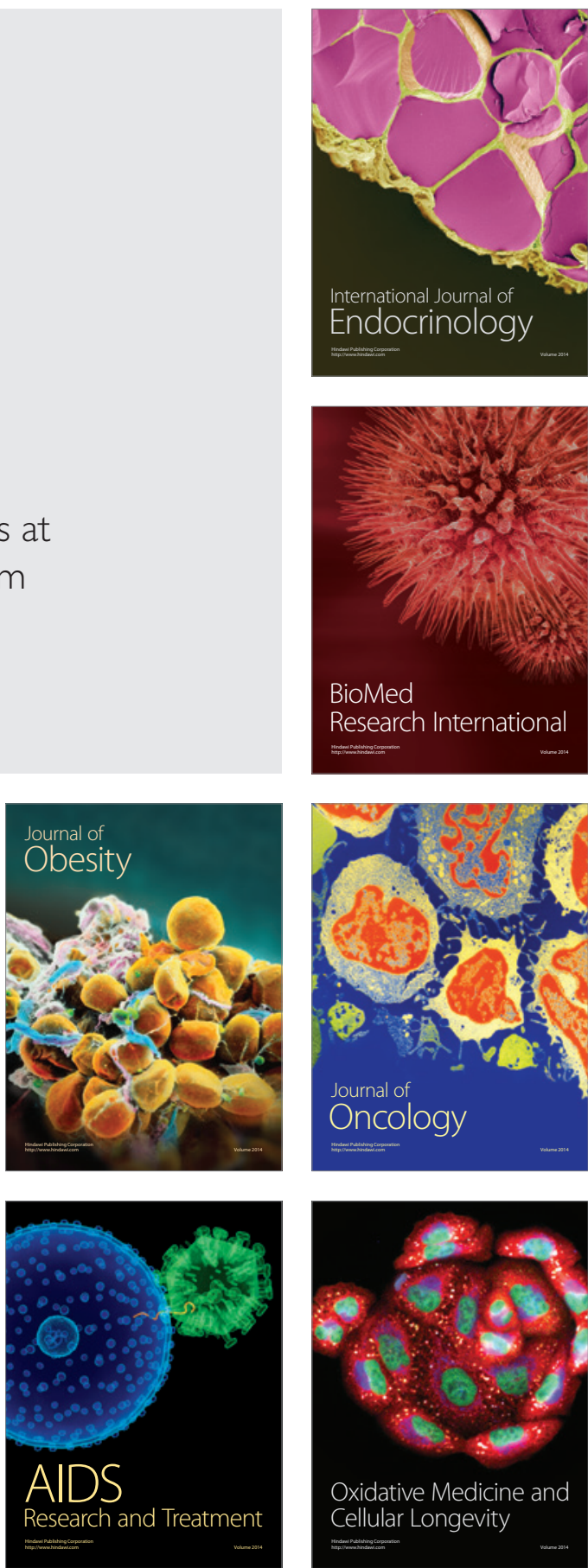